\title{
Cobalt- and rhodium-catalyzed carboxylation using carbon dioxide as the $\mathrm{C} 1$ source
}

\author{
Tetsuaki Fujihara* and Yasushi Tsuji
}

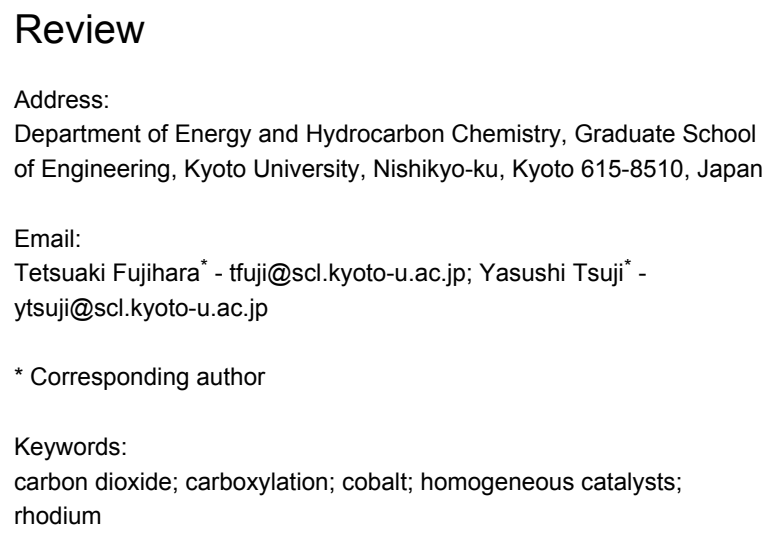

Beilstein J. Org. Chem. 2018, 14, 2435-2460.

doi:10.3762/bjoc.14.221

Received: 18 June 2018

Accepted: 28 August 2018

Published: 19 September 2018

This article is part of the thematic issue "Cobalt catalysis".

Guest Editor: S. Matsunaga

(c) 2018 Fujihara and Tsuji; licensee Beilstein-Institut. License and terms: see end of document.

\begin{abstract}
Carbon dioxide $\left(\mathrm{CO}_{2}\right)$ is one of the most important materials as renewable chemical feedstock. In this review, the Co- and Rh-catalyzed transformation of $\mathrm{CO}_{2}$ via carbon-carbon bond-forming reactions is summarized. Combinations of metals (cobalt or rhodium), substrates, and reducing agents realize efficient carboxylation reactions using $\mathrm{CO}_{2}$. The carboxylation of propargyl acetates and alkenyl triflates using cobalt complexes as well as the cobalt-catalyzed reductive carboxylation of $\alpha, \beta$-unsaturated nitriles and carboxyamides in the presence of $\mathrm{Et}_{2} \mathrm{Zn}$ proceed. A Co complex has been demonstrated to act as an efficient catalyst in the carboxylation of allylic $\mathrm{C}\left(\mathrm{sp}^{3}\right)-\mathrm{H}$ bonds. Employing zinc as the reductant, carboxyzincation and the four-component coupling reaction between alkyne, acrylates, $\mathrm{CO}_{2}$, and zinc occur efficiently. Rh complexes also catalyze the carboxylation of arylboronic esters, $\mathrm{C}\left(\mathrm{sp}^{2}\right)-\mathrm{H}$ carboxylation of aromatic compounds, and hydrocarboxylation of styrene derivatives. The Rh-catalyzed $[2+2+2]$ cycloaddition of diynes and $\mathrm{CO}_{2}$ proceeds to afford pyrones.
\end{abstract}

\section{Introduction}

Carbon dioxide $\left(\mathrm{CO}_{2}\right)$ is one of the most important materials as renewable feedstock [1-4]. However, the thermodynamic and kinetic stability of $\mathrm{CO}_{2}$ sometimes limits its utility. Classically, harsh reaction conditions such as high temperature and high pressure of $\mathrm{CO}_{2}$ were required. To overcome these problems, the use of transition-metal catalysts has been considered as a fundamental and reliable method. In the last decade, considerable attention has been focused on the development of the catalytic fixation of $\mathrm{CO}_{2}$ via carbon-carbon $(\mathrm{C}-\mathrm{C})$ bond formation using a variety of organic compounds as starting materials [5-20]. A key factor for the successful catalytic fixation of $\mathrm{CO}_{2}$ is the carbon-metal bond formation when transition metals are used as the catalyst. In addition, the choice of suitable reducing agents is also crucial for realizing effective carboxylation reactions.

In this review, the $\mathrm{Co}$ - and $\mathrm{Rh}$-catalyzed transformations of $\mathrm{CO}_{2}$ via $\mathrm{C}-\mathrm{C}$ bond-forming reactions are summarized. First, we 
describe Co-catalyzed carboxylation reactions, including the carboxylation of propargyl acetates and alkenyl triflates. Then, the Co-catalyzed reductive carboxylation of $\alpha, \beta$-unsaturated nitriles and carboxyamides is addressed. In addition, a Co catalyst can catalyze the allylic $\mathrm{C}\left(\mathrm{sp}^{3}\right)-\mathrm{H}$ carboxylation of allylarenes when a suitable ligand is used. In the presence of zinc powder, the Co-catalyzed carboxyzincation of alkynes and the four-component coupling reaction between alkyne, acrylates, $\mathrm{CO}_{2}$, and zinc proceed in an efficient manner. Visible-lightdriven hydrocarboxylation reactions are shown. We also summarize carboxylation reactions catalyzed by rhodium that is a homologous element of cobalt. Carboxylations of arylboronic esters are described. Rh complexes are also effective catalysts in $\mathrm{C}\left(\mathrm{sp}^{2}\right)-\mathrm{H}$ carboxylation reactions. Employing $\mathrm{Et}_{2} \mathrm{Zn}$ or visible light, the Rh-catalyzed hydrocarboxylation of styrene derivatives has been achieved. Furthermore, the formation of pyrones from diynes and $\mathrm{CO}_{2}$ can be effectively catalyzed by Rh complexes.

\section{Review}

\section{Cobalt catalysts}

\section{Carboxylation of propargyl acetates}

Allyl and propargyl electrophiles, such as halides and esters, are well known as efficient reagents in transition-metal-catalyzed $\mathrm{C}-\mathrm{C}$ bond-forming reactions [21-23]. In particular, the carboxylation of allyl esters with $\mathrm{CO}_{2}$ has been catalyzed by $\mathrm{Pd}$ or $\mathrm{Ni}$ under electrochemical reaction conditions [24,25]. For catalytic reactions using reducing agents, Martin reported Ni-catalyzed regiodivergent carboxylation of allyl acetates in the presence of $\mathrm{Mn}$ as the reductant [26]. Mita and Sato found that Pd-catalyzed carboxylation of allylic alcohols proceeded using $\mathrm{Et}_{2} \mathrm{Zn}$ as the reducing agent [27]. The carboxylation of propargyl chlo- ride was reported as one of the examples concerning the Ni-catalyzed carboxylation of benzyl chlorides [28].

We have found that Co complexes can catalyze the carboxylation of propargyl acetates with $\mathrm{CO}_{2}$ using $\mathrm{Mn}$ powder as the reducing agent [29]. Thus, the carboxylation of a propargyl acetate 1a was performed in the presence of $\mathrm{CoI}_{2}$ (phen) (phen = 1,10-phenanthroline) and Mn powder (3.0 equiv) in $N, N$ dimethylacetamide (DMA) under an atmospheric pressure of $\mathrm{CO}_{2}$ at room temperature (Scheme 1). Under optimized reaction conditions, the carboxylated product $\mathbf{2 a - M e}$ was obtained in $83 \%$ yield after derivatization to the corresponding methyl ester. In the absence of the Co catalyst, 2a-Me was not obtained. Moreover, Mn powder proved to be essential for the carboxylation to proceed. Using $\mathrm{CoI}_{2}$ (bpy) (bpy $=2,2^{\prime}$-bipyridine) as the catalyst afforded $\mathbf{2 a - M e}$ in $76 \%$ yield, whereas $\mathrm{CoI}_{2}\left(\mathrm{PPh}_{3}\right)_{2}$ and $\mathrm{CoI}_{2}$ (dppe) (dppe $=1$,2-bis(diphenylphosphino)ethane) suppressed the carboxylation.

The carboxylation of various propargyl acetates containing the trimethylsilyl (TMS) group as the $\mathrm{R}^{1}$ group proceeded under the optimal reaction conditions, affording the corresponding carboxylic acids $\mathbf{2 b}-\mathbf{e}$ in good-to-high yields (Scheme 2). Notably, the ester and chloro functionalities in $\mathbf{2 b}$ and $\mathbf{2 c}$, respectively, were compatible with the reaction conditions. For the carboxylation of tertiary-alcohol-derived acetates to the corresponding carboxylic acids $\mathbf{2 d}, \mathbf{e}, \mathrm{CoI}_{2}$ (bpy) was found to be an effective catalyst. The yields of product $\mathbf{2}$ decreased when less bulky substituents $\left(\mathrm{R}^{1}\right)$ were used. Thus, $\mathbf{1 f}\left(\mathrm{R}^{1}=\right.$ tert-butyldimethylsilyl) afforded the corresponding product $\mathbf{2 f}$ in $88 \%$ yield, whereas $\mathbf{1 g}\left(\mathrm{R}^{1}=t-\mathrm{Bu}\right)$ and $\mathbf{1 h}\left(\mathrm{R}^{1}=\mathrm{Cy}\right)$ afforded $\mathbf{2 g}$ and $\mathbf{2 h}$ in $57 \%$ and $26 \%$ yields, respectively.
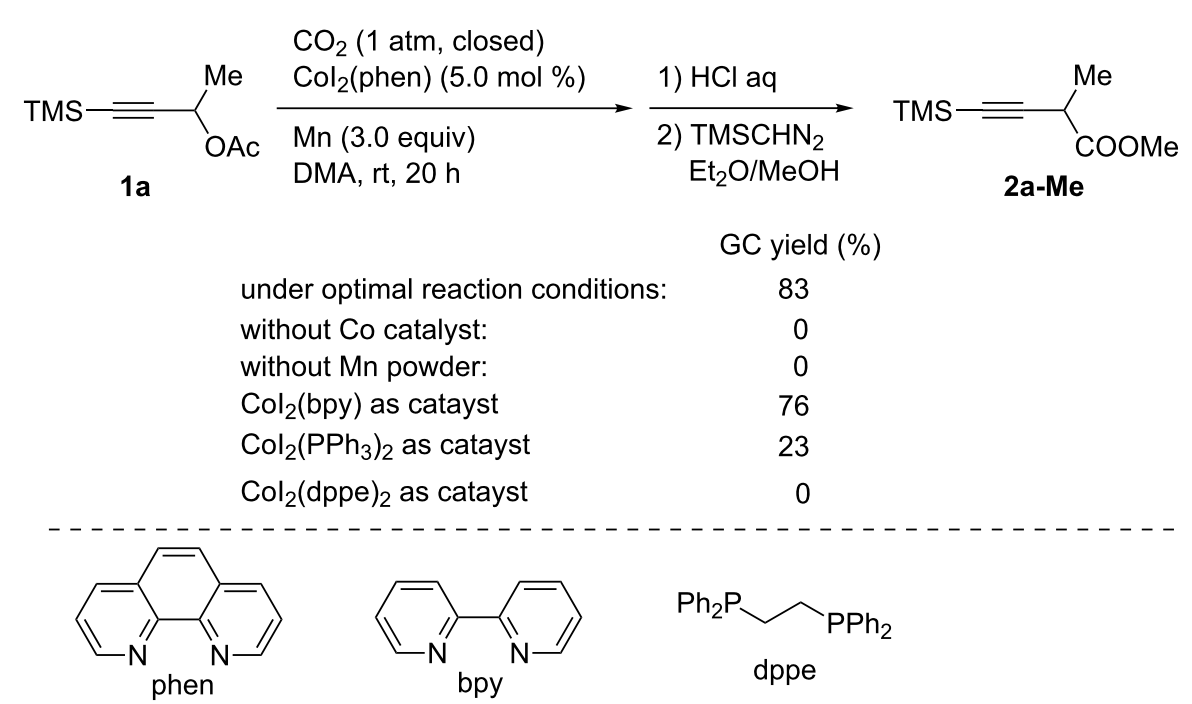

Scheme 1: Optimization of the Co-catalyzed carboxylation of 1a. 


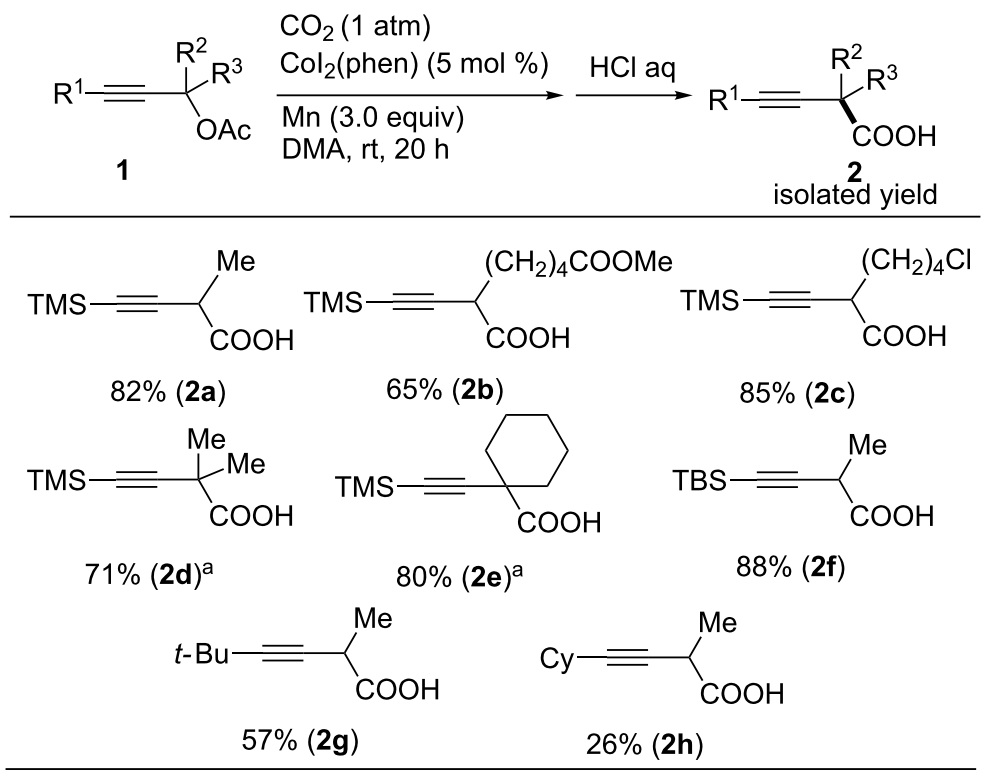

${ }^{\mathrm{a}} \mathrm{Col}_{2}$ (bpy) $(5.0 \mathrm{~mol} \%)$ was used as the catalyst
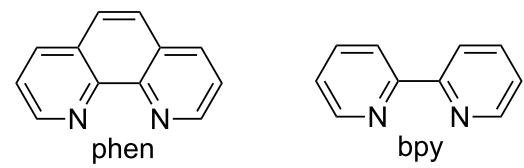

Scheme 2: Co-catalyzed carboxylation of propargyl acetates 1.

Scheme 3 presents a plausible reaction mechanism for this transformation. Accordingly, a Co(I) catalytic species A is first generated by the reduction of Co(II) with Mn. Secondly, the oxidative addition of the $\mathrm{C}-\mathrm{O}$ bond in $\mathbf{1}$ occurs, affording $\mathrm{Co}(\mathrm{III})$ intermediate B (step a) [30]. Next, the propargyl Co(III) species $\mathbf{B}$ is reduced by $\mathrm{Mn}$, producing the corresponding propargyl Co(II) intermediate $\mathbf{C}$ (step b). Subsequently, the nucleophilic Co species $\mathbf{C}$ reacts with $\mathrm{CO}_{2}$, which provides carboxylate

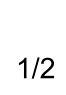<smiles>[R]C#CC([R])([R])[O-]</smiles>

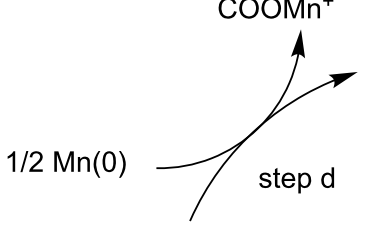<smiles>[R]C#CC([R])([R])C(=O)O[Na]</smiles><smiles></smiles><smiles>[Mg][Mg]</smiles><smiles>COC(=O)C(C)(C)C(C)C</smiles>

$\operatorname{CoXL}_{n}$

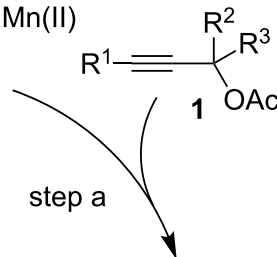<smiles>[R]C#CC([R])([R])C([R])O[R]</smiles>

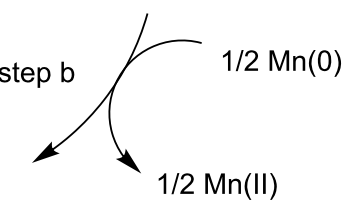


Co(II) intermediate $\mathbf{D}$ (step c). Finally, the reduction of $\mathbf{D}$ with Mn affords the corresponding carboxylate, regenerating the Co(I) catalytic species A (step d).

\section{Carboxylation of alkenyl and aryl triflates}

The catalytic carboxylation of aryl halides and pseudohalides using $\mathrm{CO}_{2}$ is an important reaction to yield benzoic acid derivatives. In 2009, Martin reported the Pd-catalyzed carboxylation of aryl bromides using $\mathrm{ZnEt}_{2}$ as the reductant [31]. In 2012, we first reported the Ni-catalyzed carboxylation of aryl chlorides and vinyl chlorides using Mn powder as the suitable reductant [32]. These reactions can be performed under mild conditions, i.e., an atmospheric pressure of $\mathrm{CO}_{2}$ at room temperature.

We also reported the Co-catalyzed carboxylation of alkenyl and aryl trifluoromethanesulfonates (triflates) as substrates [33]. As a model reaction (Scheme 4), alkenyl triflate $\mathbf{3 a}$ was selected as the substrate, and the carboxylation of $\mathbf{3 a}$ was performed using Mn powder (1.5 equiv) as the reductant in DMA as the solvent under an atmospheric pressure of $\mathrm{CO}_{2}$ at room temperature. Employing $\mathrm{CoI}_{2}$ ( $\mathrm{Me}_{2}$ phen) $\left(\mathrm{Me}_{2}\right.$ phen $=2,9$-dimethyl-1,10phenanthroline) as the catalyst, 4a-Me was obtained in $86 \%$ yield after esterification. Other bidentate ligands such as bpy, phen, and dppe were not suitable for this reaction. Control experiments revealed that both the Co catalyst and the Mn reductant were indispensable to the reaction.

The carboxylation of diverse alkenyl triflates was also examined. As a result, the desired carboxylic acids $\mathbf{4 a - k}$ were ob- tained in good-to-high yields, as shown in Scheme 5. Notably, the ester and $p$-toluenesulfonate functionalities in $\mathbf{4 c}$ and $\mathbf{4 d}$, respectively, were tolerated. An indole-functionalized substrate $\mathbf{3 f}$ was converted into its corresponding carboxylic acid $\mathbf{4 f}$. Conjugated alkenyl triflates $\mathbf{3 g}-\mathbf{i}$ were also subjected to the reaction, and the desired carboxylic acids $\mathbf{4} \mathbf{g}-\mathbf{i}$ were obtained in moderate-to-high yields. Furthermore, the seven-membered cyclic substrate $\mathbf{3} \mathbf{j}$ that was derived from cycloheptanone afforded its corresponding conjugated carboxylic acid $\mathbf{4 j}$ in $75 \%$ yield. The alkenyl triflate $\mathbf{3 k}$ prepared from the corresponding aldehyde was also carboxylated, and its corresponding product $\mathbf{4 k}$ was obtained in moderate yield.

The catalyst $\mathrm{CoI}_{2}\left(\mathrm{Me}_{2}\right.$ phen) was also effective with sterically hindered aryl triflates: the carboxylation of mesityl triflate (5) at $40{ }^{\circ} \mathrm{C}$ proceeded successfully, affording 6 in $77 \%$ yield (Scheme 6)

\section{Carboxylation of $\alpha, \beta$-unsaturated nitriles and esters}

$\alpha, \beta$-Unsaturated carbonyl compounds are good substrates for conjugate additions that use a catalytic amount of a metal complex and a stoichiometric amount of reductant, as exemplified by the reductive aldol reaction of $\alpha, \beta$-unsaturated nitriles catalyzed by cobalt using phenylsilane as the reductant [34].

Yamada found that the reductive carboxylation of $\alpha, \beta$-unsaturated compounds with $\mathrm{CO}_{2}$ proceeded in the presence of $\mathrm{Co}$ catalysts and reductants (Scheme 7) $[35,36]$. When the reaction of 5-phenylpent-2-enenitrile (7a) was performed in the pres-

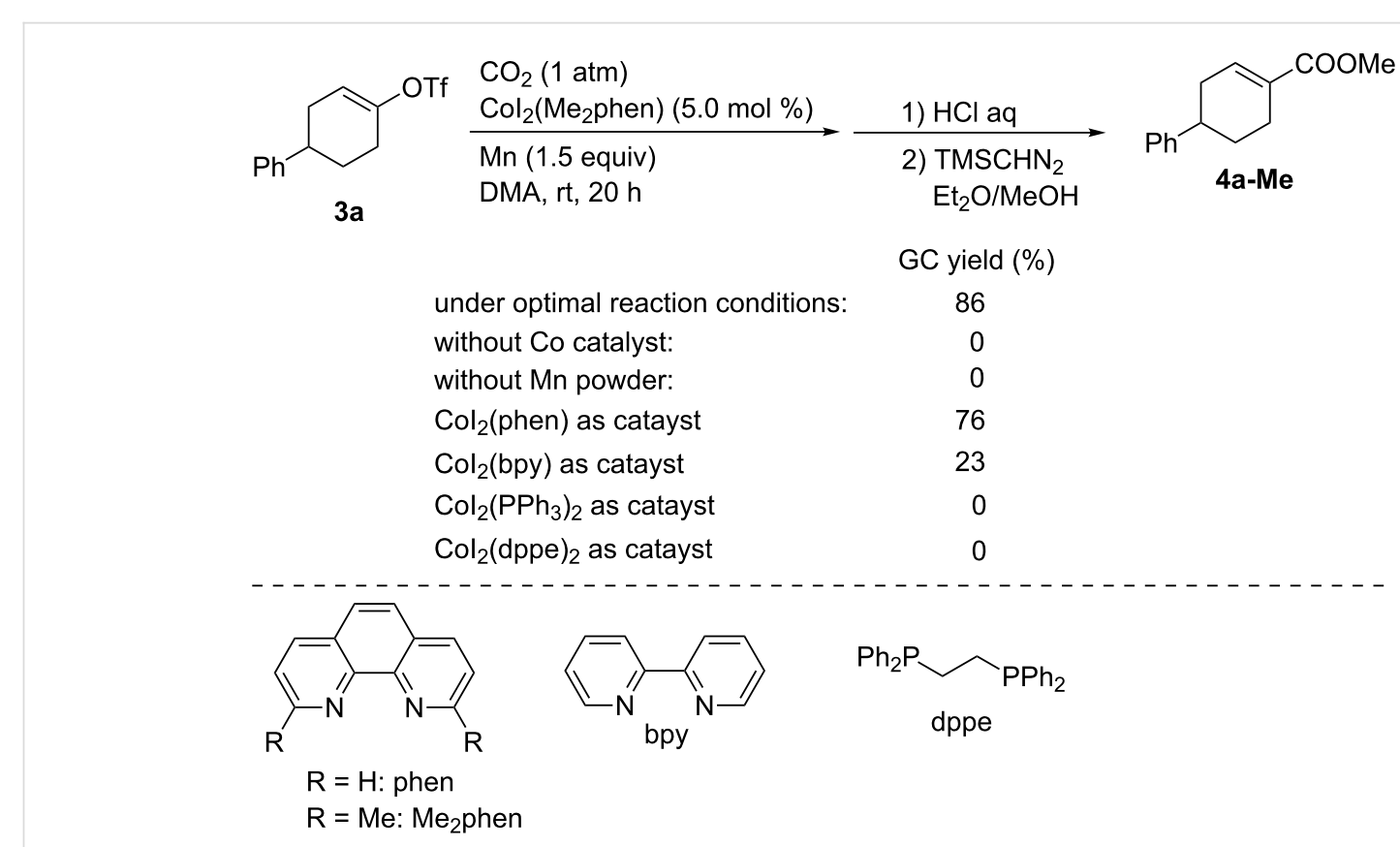

Scheme 4: Optimization of the Co-catalyzed carboxylation of $3 a$ 


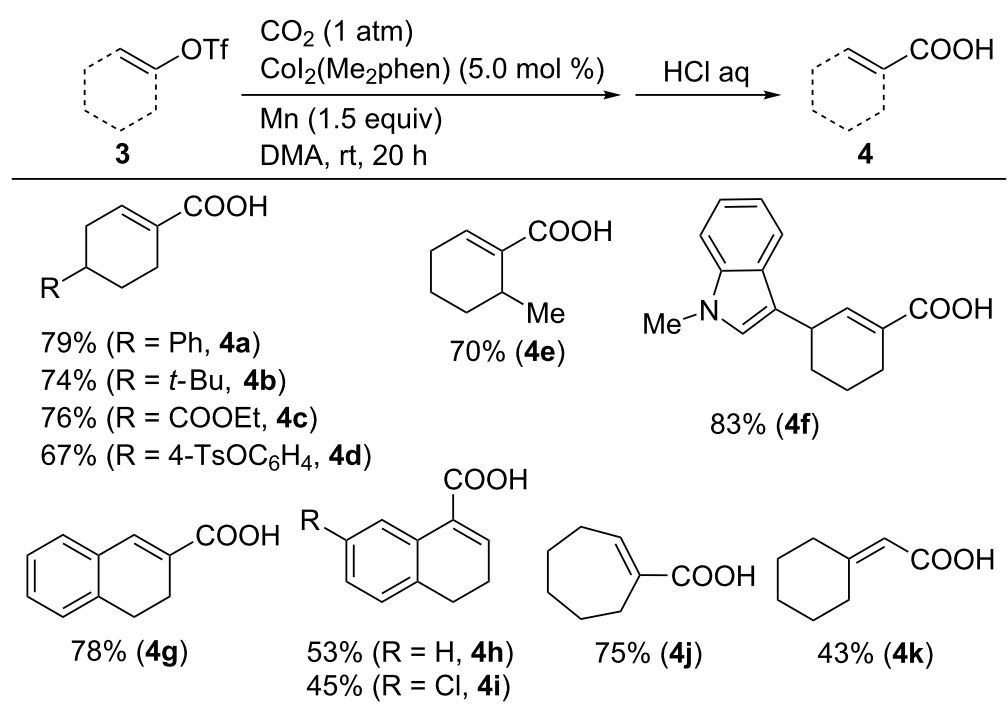

Scheme 5: Co-catalyzed carboxylation of vinyl triflates 3.

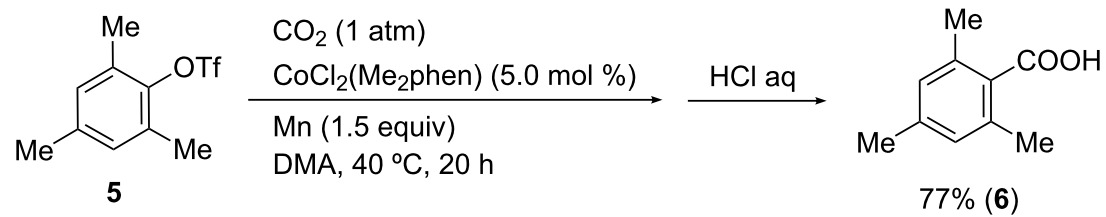

Scheme 6: Co-catalyzed carboxylation of a sterically hindered aryl triflate $\mathbf{5}$.

\begin{tabular}{|c|c|c|c|c|}
\hline \multirow[b]{3}{*}{$\begin{array}{l}\text { reducing } \\
\text { agent }\end{array}$} & \multirow{3}{*}{$\begin{array}{l}\text { CN } \\
\text { amount of } \\
(\mathrm{mol} \%)\end{array}$} & \multirow{2}{*}{\multicolumn{2}{|c|}{$\begin{array}{l}\mathrm{CO}_{2} \\
\text { cat. } \mathrm{Co}(\mathrm{acac})_{2} \\
\text { educing agent ( } 2.0 \text { equiv }) \\
\mathrm{THF}, 20^{\circ} \mathrm{C}\end{array}$}} & \multirow{3}{*}{$\begin{array}{l}\mathrm{R}=\mathrm{H}: \mathbf{8 a} \\
\mathrm{R}=\mathrm{Me}: \mathbf{8 a}-\mathbf{M e} \\
\text { yield (\%) }\end{array}$} \\
\hline & & & & \\
\hline & & $\mathrm{Co}(\mathrm{acac})_{2}$ & $\begin{array}{l}\mathrm{CO}_{2} \text { pressure } \\
(\mathrm{MPa})\end{array}$ & \\
\hline$E t_{2} Z n$ & & 5 & 0.1 & 99 (8a-Me) \\
\hline $\mathrm{Et}_{2} \mathrm{Zn}$ & & 5 & 1.0 & 87 (8a-Me) \\
\hline $\mathrm{Et}_{2} \mathrm{Zn}$ & 100 & & 1.3 & $62(8 a)$ \\
\hline $\mathrm{Et}_{2} \mathrm{AlCl}$ & 100 & & 1.3 & $26(8 a)$ \\
\hline $\mathrm{Et}_{3} \mathrm{~B}$ & 100 & & 1.0 & $10(8 a)$ \\
\hline
\end{tabular}

Scheme 7: Optimization of the Co-catalyzed carboxylation of $7 \mathbf{a}$.

ence of catalytic $\mathrm{Co}(\mathrm{acac})_{2}$ and with $\mathrm{Et}_{2} \mathrm{Zn}$ as the reductant, the carboxylation proceeded to yield $\mathbf{8 a - M e}$ after its derivatization to the corresponding methyl ester. In these reactions, the selection of the reductant is crucial: other reductants such as $\mathrm{Et}_{2} \mathrm{AlCl}$ and $\mathrm{Et}_{3} \mathrm{~B}$ yielded the corresponding product in low yields even after using a stoichiometric amount of $\mathrm{Co}(\mathrm{acac})_{2}$ at high pressure.
Under the optimal reaction conditions with the $\mathrm{Co}(\mathrm{acac})_{2} / \mathrm{Et}_{2} \mathrm{Zn}$ system, various $\alpha, \beta$-unsaturated nitriles were carboxylated to the corresponding products, which were isolated as methyl esters (Scheme 8). Thus, compound 7 bearing alkyl, ether, ester, and halide substituents exhibited good reactivity. Cinnamonitrile afforded $\mathbf{8 f - M e}$ in $81 \%$ yield using $10 \mathrm{~mol} \%$ of catalyst. $\alpha$-Phenyl-substituted $\alpha, \beta$-unsaturated nitrile also reacted with 


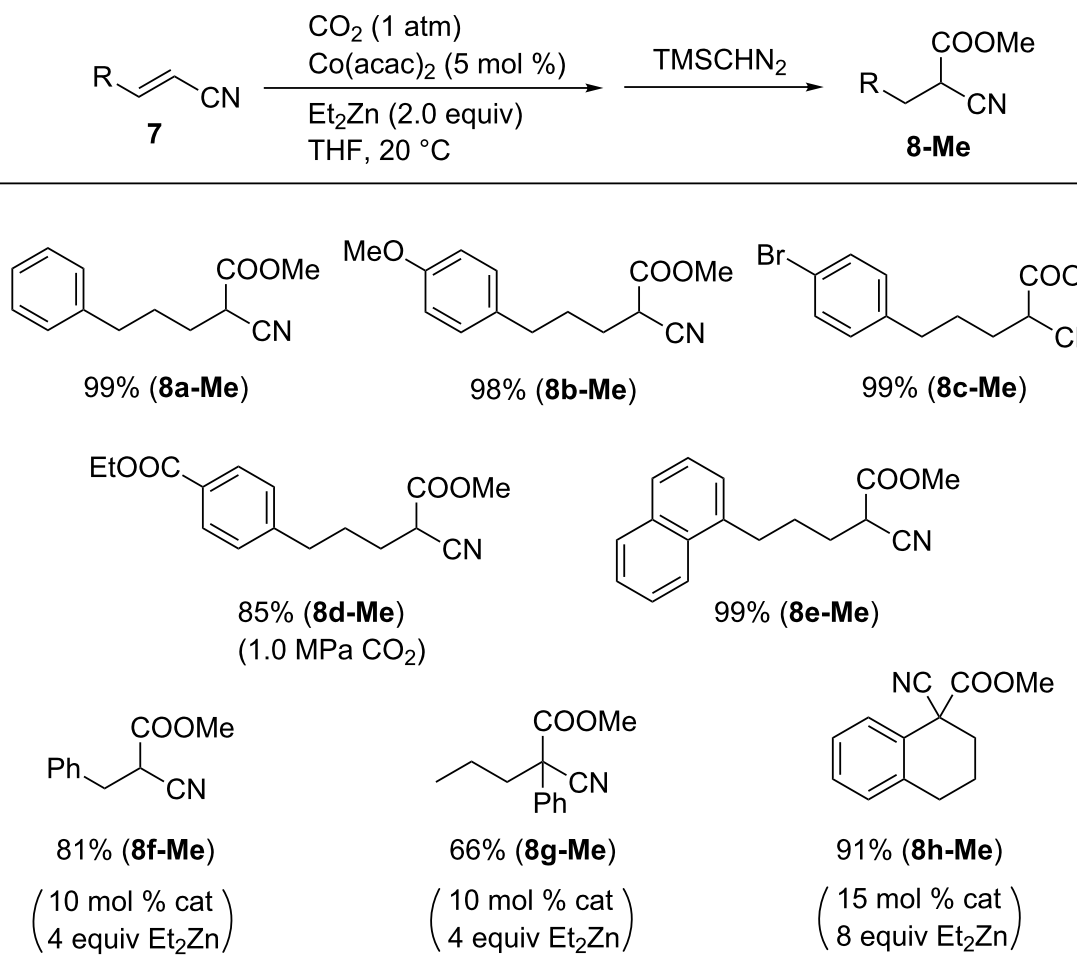

Scheme 8: Scope of the reductive carboxylation of $\alpha, \beta$-unsaturated nitriles 7 .

$\mathrm{CO}_{2}$, affording the carboxylated product $\mathbf{8 g}-\mathbf{M e}$ in good yield. In addition, compound $\mathbf{8 h - M e}$ was obtained from the reaction of $\alpha$-cyano-substituted dihydronaphthalene $7 \mathbf{h}$ with $\mathrm{CO}_{2}$ in the presence of $15 \mathrm{~mol} \%$ of catalyst and 8 equiv of $\mathrm{Et}_{2} \mathrm{Zn}$.

The $\mathrm{Co}(\mathrm{acac})_{2} / \mathrm{Et}_{2} \mathrm{Zn}$ system can also be applied to carboxylate $\alpha, \beta$-unsaturated carboxamides 9 (Scheme 9). By using $10 \mathrm{~mol} \%$ of $\mathrm{Co}(\mathrm{acac})_{2}$ and 4 equiv of $\mathrm{Et}_{2} \mathrm{Zn}, \mathrm{N}$-methylanilide derivatives 9a-f were smoothly converted into the corresponding products 10a-f in high yields. Trifluoromethyl and chloro substituents were tolerated in these reactions, judging by the formation of products $\mathbf{1 0 c - M e}$ and 10d-Me. With regard to other amide groups, morpholides $\mathbf{9 g}-\mathbf{i}$ could be used and benzylmethylamide- and diethylamide-bearing substrates, which afforded the corresponding products $10 \mathbf{j}$-Me and 10k-Me, albeit with moderate yields.

\section{Allylic $\mathrm{C}\left(\mathrm{sp}^{3}\right)-\mathrm{H}$ bond carboxylation}

The development of methods for the catalytic carboxylation of less reactive $\mathrm{C}-\mathrm{H}$ bonds with $\mathrm{CO}_{2}$ is crucial regarding both $\mathrm{C}-\mathrm{H}$ activation and $\mathrm{CO}_{2}$ fixation processes. Mita and Sato reported a cobalt-catalyzed allylic $\mathrm{C}-\mathrm{H}$ carboxylation of allylarenes (Scheme 10), in which 1-allyl-4-phenylbenzene (11a) was reacted with $\mathrm{CO}_{2}(1 \mathrm{~atm})$ in the presence of $\mathrm{AlMe}_{3}$ ( 3 equiv) using catalytic amounts of a Co precursor and ligands
[37]. The catalytic system comprising $\mathrm{Co}(\mathrm{acac})_{2}$ and Xantphos (4,5-bis(diphenylphosphino)-9,9-dimethylxanthene) afforded the corresponding carboxylated product 12a-Me in an NMR yield of $71 \%$ after $\mathrm{CH}_{2} \mathrm{~N}_{2}$ treatment. In the reaction mixture, olefin isomers were also generated in $20 \%$ yield. The ligands were found to have a strong influence in yields and selectivity. Thus, the use of DPEphos (2,2'-bis(diphenylphosphino)diphenyl ether), dppf (1,1'-bis(diphenylphosphino)ferrocene), dppp (1,3-bis(diphenylphosphino)propane), and bpy as ligands afforded the olefin isomerization product as the major product. Further screening of the reaction conditions revealed that the amount of $\mathrm{AlMe}_{3}$ was critical: the product yield increased with decreasing $\mathrm{AlMe}_{3}$ to 1.5 equiv. The concentration of $11 \mathrm{a}$ also affected the efficiency of the reaction, and the isomerization of olefins could be suppressed at lower concentrations of 11a, affording the desired 12a-Me in 58\% yield. With the addition of 1 equiv of $\mathrm{CsF}$, the carboxylation was further accelerated to give 12a-Me in $71 \%$ yield.

Using optimized reaction conditions, the substrate scope was examined (Scheme 11). Allylbenzene was converted into its corresponding carboxylated product 12a in an isolated 68\% yield, and various functionalized allylarenes bearing trifluoromethyl (11b) and alkoxy (11c,d) substituents were tolerated. The selectivity of the reaction was demonstrated with 


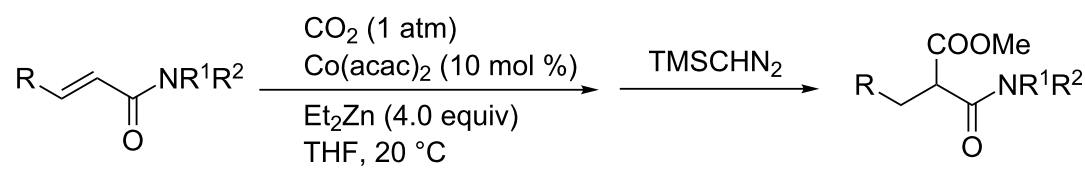

9

10-Me<smiles>COC(=O)C(Cc1ccccc1N(C)C(=O)C(CCCc1ccccc1)C(=O)OC)C(=O)N(C)c1ccccc1</smiles>

$99 \%(10 a-M e)$<smiles>COC(=O)C(Cc1ccc(Cl)cc1)C(=O)N(C)c1ccccc1</smiles>

$67 \%$ (10d-Me)
$88 \%(10 \mathrm{~b}-\mathrm{Me})$<smiles>CCC(C(=O)OC)C(=O)N(C)c1ccccc1</smiles>

$80 \%$ (10e-Me)<smiles>COC(=O)C(Cc1ccc(C(F)(F)F)cc1)C(=O)N(C)c1ccccc1</smiles>

98\% (10c-Me)<smiles>CCCCCCC(C(=O)OC)C(=O)N(C)c1ccccc1</smiles>

$20 \%$ (10f-Me)<smiles>COC(=O)C(CCCc1ccccc1)C(=O)N1CCOCC1</smiles>

$92 \%(10 \mathrm{~g}-\mathrm{Me})$<smiles>COC(=O)C(Cc1ccccc1)C(=O)N1CCOCC1</smiles>

$68 \%$ (10h-Me)<smiles>COC(=O)C(Cc1ccc(Cl)cc1)C(=O)N1CCOCC1</smiles>

$75 \%$ (10i-Me)<smiles>COC(=O)C(CCCc1ccccc1)C(=O)N(C)Cc1ccccc1</smiles>

$64 \%(10 \mathrm{j}-\mathrm{Me})$<smiles>CCN(CC)C(=O)C(CCCc1ccccc1)C(=O)OC</smiles>

$62 \%(10 k-M e)$

Scheme 9: Scope of the carboxylation of $\alpha, \beta$-unsaturated carboxamides 9 .

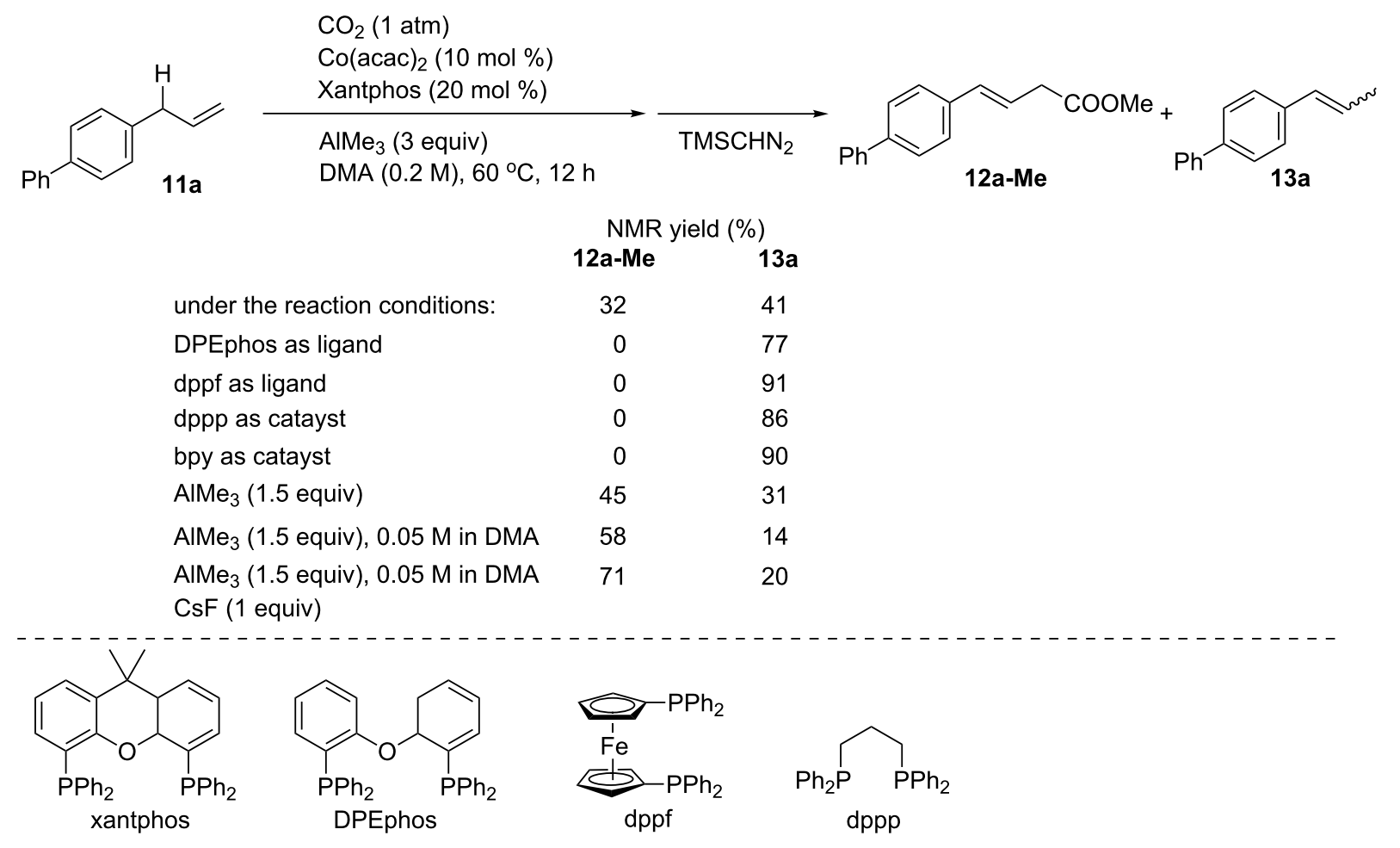

Scheme 10: Optimization of the Co-catalyzed carboxylation of 11a. 

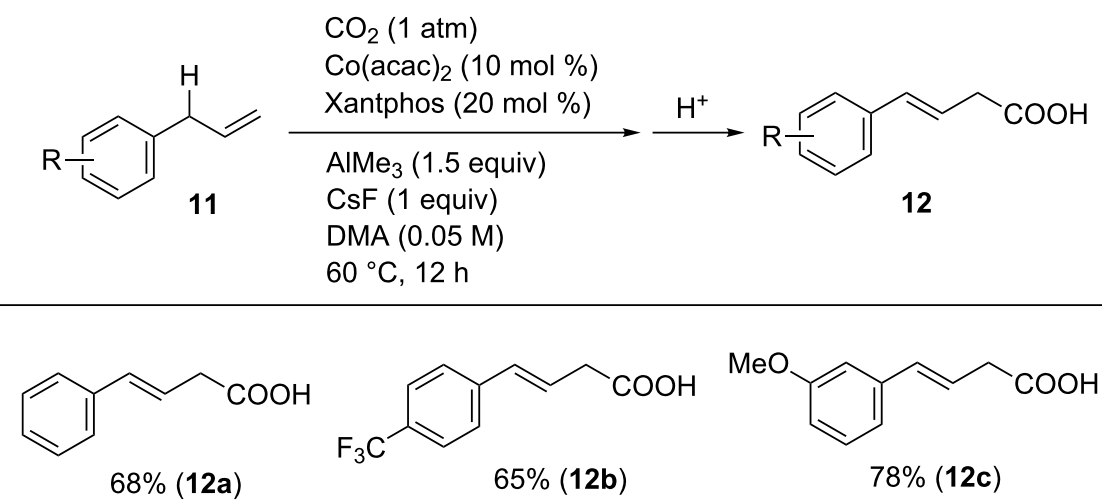<smiles>O=C(O)CC=Cc1ccc2c(c1)OCO2</smiles>

$69 \%(12 d)$<smiles>O=C(O)C/C=C/c1ccccc1-c1ccccc1</smiles>

$63 \%(12 e)$<smiles>O=C(O)C/C=C/c1ccc2ccccc2c1</smiles>

$41 \%(\mathbf{1 2 f})$<smiles>COC(=O)c1ccc(/C=C/CC(=O)O)cc1</smiles><smiles>O=C(O)C/C=C/c1ccc(C(=O)c2ccccc2)cc1</smiles>

Scheme 11: Scope of the carboxylation of allylarenes 11.

substrates $11 \mathrm{~g}$ and $11 \mathrm{~h}$ containing ester and ketone moieties, respectively, which are generally more reactive toward nucleophiles than $\mathrm{CO}_{2}$.

Notably, the Co-catalyst system was found to be applicable for the carboxylation of 1,3-diene derivatives 14 with $\mathrm{CO}_{2}$
(Scheme 12), which afforded various hexa-3,5-dienoic acid derivatives. Diene 14a was converted into the corresponding carboxylic acid 15a in good yield. In addition, 1,4-dienes having cyclohexenyl and geminal diphenyl substituents (14b and $14 \mathrm{c}$ ) produced their corresponding linear carboxylic acids $\mathbf{1 5 b}$ and $\mathbf{1 5 c}$ in $78 \%$ and $57 \%$ yields, respectively. Substrate $\mathbf{1 4 e}$

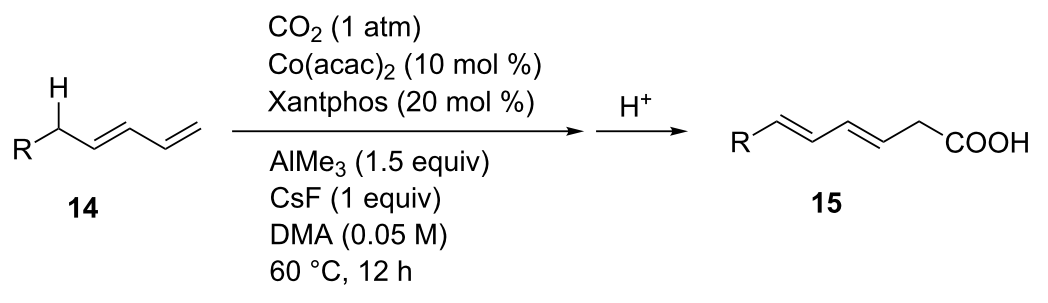

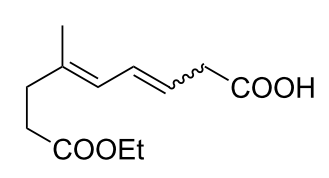

$75 \%$

$(15 a, E / Z=90: 10)$<smiles>CCOC(=O)CCC(C)=C(C)C=CCC(=O)O</smiles>

$68 \%(15 d, E / Z=55: 45)$ from $14 d(E / Z=50: 50)$<smiles>O=C(O)CC=CC1=CCC(c2ccccc2)CC1</smiles>

$78 \%(15 b)$<smiles>CC(/C=C/CC(=O)O)=C(c1ccccc1)c1ccccc1</smiles>

$57 \%(15 c)$

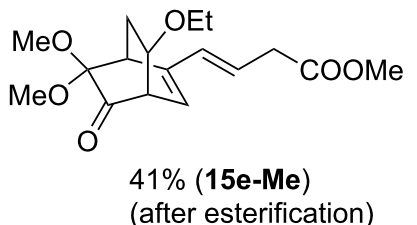


containing a bicyclo[2.2.2] octane framework with ketone and dimethyl ketal moieties was also converted and the corresponding product was isolated as the methyl ester 15e-Me after esterification.

For the Co-catalyzed $\mathrm{C}\left(\mathrm{sp}^{3}\right)-\mathrm{H}$ carboxylation of allylarenes, a mechanism shown in Scheme 13 can be envisaged. The process starts with the generation of a low-valent methyl-Co(I) species A by the reaction of the $\mathrm{Co}(\mathrm{II})$ complex with $\mathrm{AlMe}_{3}$. The $\mathrm{C}-\mathrm{C}$ double bond of the substrate then coordinates to the metal, and

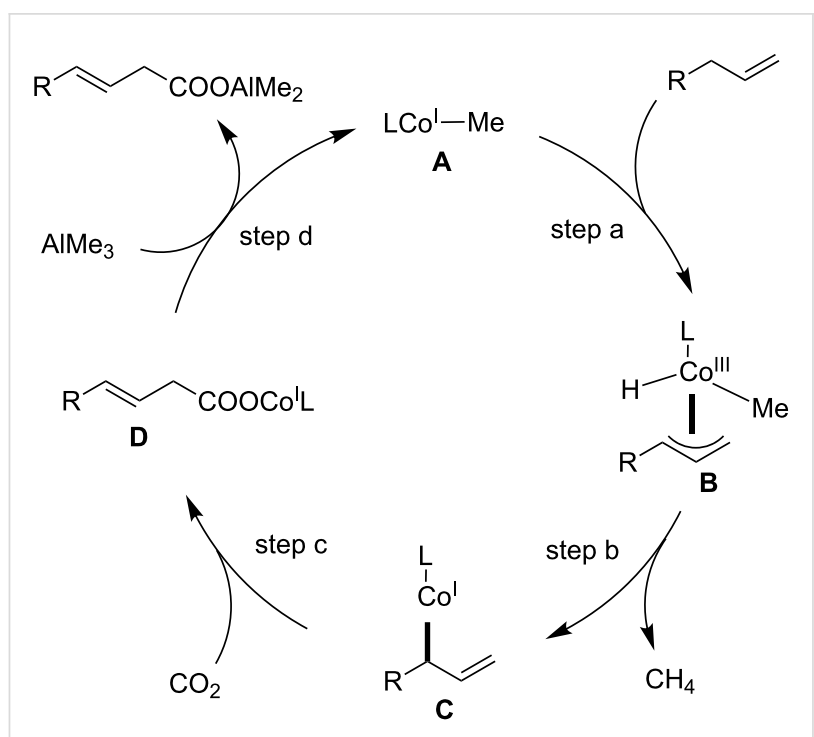

Scheme 13: Plausible reaction mechanism for the Co-catalyzed $\mathrm{C}\left(\mathrm{sp}^{3}\right)-\mathrm{H}$ carboxylation of allylarenes. the subsequent cleavage of the adjacent allylic $\mathrm{C}-\mathrm{H}$ bond affords $\eta^{3}$-allyl-Co(III) species B (step a). Subsequently, the reductive elimination of methane from $\mathbf{B}$ yields the low-valent allyl-Co(I) species $\mathbf{C}$ (step b). Then, $\mathrm{C}-\mathrm{C}$ bond formation at the $\gamma$-position occurs via a reaction with $\mathrm{CO}_{2}$, affording the carboxylate Co species D (step c). Finally, a linear carboxylated product is obtained by the transmetalation between $\mathbf{D}$ and $\mathrm{AlMe}_{3}$, with the concomitant regeneration of methyl-Co(I) A (step d).

\section{Carboxyzincation of alkynes}

The good reactivity and high functional-group compatibility of organozinc compounds render them as important reagents in organic synthesis $[38,39]$. For their preparation, direct and useful methods such as the transition-metal-catalyzed carbozincation of alkynes that affords stereodefined alkenylzinc compounds have been developed. To date, a variety of organozinc reagents ( $\mathrm{RZnX}$ and $\mathrm{R}_{2} \mathrm{Zn}$ : $\mathrm{R}$ = aryl, alkyl, alkenyl, alkynyl, allyl, and benzyl groups) have been used in these reactions, and the corresponding alkenylzinc compounds can be prepared.

In this context, we reported the first carboxyzincation of alkynes using $\mathrm{CO}_{2}$ and $\mathrm{Zn}$ metal powder in the presence of a cobalt complex as the catalyst (Scheme 14) [40]. 5-Decyne (16a) was treated with $\mathrm{Zn}$ powder (1.5 equiv) in the presence of $\mathrm{CoI}_{2}(\mathrm{dppf})(10 \mathrm{~mol} \%), \mathrm{Zn}(\mathrm{OAc})_{2}(10 \mathrm{~mol} \%)$, and $\mathrm{Et}_{4} \mathrm{NI}$ $(10 \mathrm{~mol} \%)$ in a mixture of $\mathrm{CH}_{3} \mathrm{CN}$ and DMF $(\mathrm{v} / \mathrm{v}=10: 1)$ under an atmospheric pressure of $\mathrm{CO}_{2}$ at $40{ }^{\circ} \mathrm{C}$. When the reaction mixture was quenched with $\mathrm{D}_{2} \mathrm{O}(>99 \% \mathrm{D})$, deuterated 17a-D was obtained in a ${ }^{1} \mathrm{H}$ NMR yield of $80 \%$ with excellent deuterium incorporation ratio $(94 \%)$ at the $\beta$-position. Al-

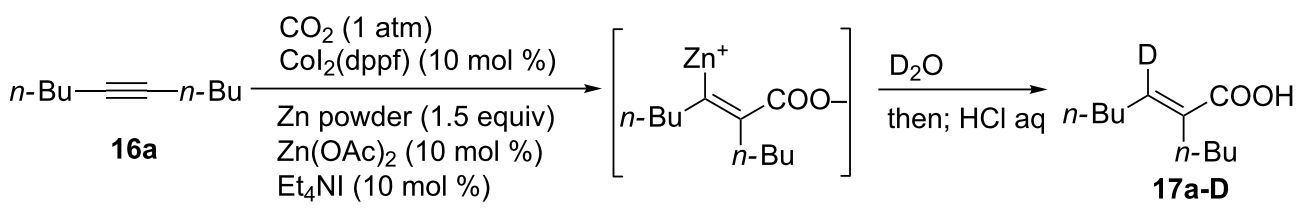

$$
\begin{aligned}
& \mathrm{CH}_{3} \mathrm{CN} / \mathrm{DMF}, 40^{\circ} \mathrm{C} \\
& \text { NMR yield (\%) } \\
& \text { under optimal reaction conditions: } \quad 86 \\
& \text { without Co catalyst: } 0 \\
& \text { without } \mathrm{Zn}(\mathrm{OAc})_{2} \text { : } \quad 53 \\
& \text { without } \mathrm{Et}_{4} \mathrm{NI} \quad 43 \\
& \mathrm{Col}_{2} \text { (dppe) as catayst } \quad<5 \\
& \mathrm{Col}_{2} \text { (bpy) as catayst } 0
\end{aligned}
$$
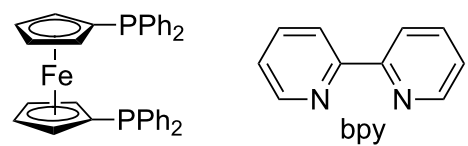
though $\mathrm{Zn}(\mathrm{OAc})_{2}$ and $\mathrm{Et}_{4} \mathrm{NI}$ were not indispensable for the reaction to proceed, these two additives caused an increased product yield. In contrast, the reaction did not occur in the absence of the catalyst. The use of the dppf ligand also proved to be essential, because other ligands such as dppe and bpy were not effective in the reaction.

After the reaction with 4-octyne (17b) under the aforementioned conditions, the reactions with $\mathrm{I}_{2}$ and $(\mathrm{PhSe})_{2}$ produced 17b-I and 17b-Se in good yields (Scheme 15). Notably, 16b was successfully subjected to the Pd-catalyzed Negishi coupling with aryl bromide, affording the corresponding sterically congested alkene $\mathbf{1 7 b}$-Ar in $56 \%$ yield after two steps. The Negishi coupling with benzyl chloride and the $\mathrm{Cu}$-catalyzed allylation of allyl bromide also afforded the corresponding products $\mathbf{1 7 b}$-Bn and $\mathbf{1 7 b}$-Allyl, respectively, in good yields.

The reaction successfully proceeded even with unsymmetrical internal alkynes. For instance, 1-(1-naphthyl)-1-hexyne (16c) afforded 17c-D in $82 \%$ yield with excellent regioselectivity (Scheme 16). Thienyl-substituted alkynes such as $\mathbf{1 6 d}$ and $\mathbf{1 6 e}$ selectively furnished 17d-D, 17d-Allyl, and 17e-D. Unsymmetrical internal alkynes bearing $4-\mathrm{Me}_{2} \mathrm{NC}_{6} \mathrm{H}_{4}$ and $4-\mathrm{MeOC}_{6} \mathrm{H}_{4}$ moieties (16f and 16g) afforded 17f-D, 17g-D, and 17g-Ar regioselectively after treatment with $\mathrm{D}_{2} \mathrm{O}$ or aryl iodide/Pd catalyst.

A possible reaction mechanism for the carboxyzincation reaction is displayed in Scheme 17. First, the Co(II) precursor is reduced to $\mathrm{Co}(\mathrm{I})(\mathrm{A})$ in the presence of metallic $\mathrm{Zn}$. The oxidative cyclization of $\mathbf{A}$ with alkyne $\mathbf{1 6}$ and $\mathrm{CO}_{2}$ affords cobaltacycle $\mathbf{B}$ (step a). Next, the transmetalation between $\mathbf{B}$ and the $\mathrm{Zn}$ (II) species occurs, which affords the alkenylzinc intermediate $\mathbf{C}$ (step b) [41], which is then reduced with $\mathrm{Zn}$ powder, thereby giving the carboxyzincated product and regenerating Co(I) species A (step c).

We also achieved the four-component coupling of alkynes 16, acrylates 18, $\mathrm{CO}_{2}$, and $\mathrm{Zn}$ metal, as depicted in Scheme 18 [40]. As a model reaction, the reaction using diphenylacetylene (16h), butyl acrylate (18a), $\mathrm{CO}_{2}$, and $\mathrm{Zn}$ was performed. After treatment with $\mathrm{H}_{2} \mathrm{O}$ and allyl bromide, the corresponding products 19a-H and 19a-Allyl were obtained in high yields. Chloro and trifluoromethyl functionalities were well tolerated under the reaction conditions, and 19b-Me and 19c-Me were obtained in $55 \%$ and $57 \%$ yields, respectively. The reaction of unsymmetrical 1-phenyl-1-hexyne with 18a afforded 19d-H and 19d-Et regioselectively. In addition, an alkyne with a thiophene ring regioselectively produced the desired product 19e-Me after methylation with MeI. It is noteworthy that an alkynoate was also converted into the corresponding product 19f-Me in good yield. Methyl, ethyl, and tert-butyl acrylates $\mathbf{1 8 b}, \mathbf{1 8 c}$, and 18d, respectively, also afforded the corresponding products. The product of the reaction with acrylamide $\mathbf{1 8 e}$ was also obtained.

Scheme 19 shows a plausible reaction mechanism for this fourcomponent coupling reaction. In a similar manner to that described for the carboxyzincation, the reduction of the $\mathrm{Co}$ (II)

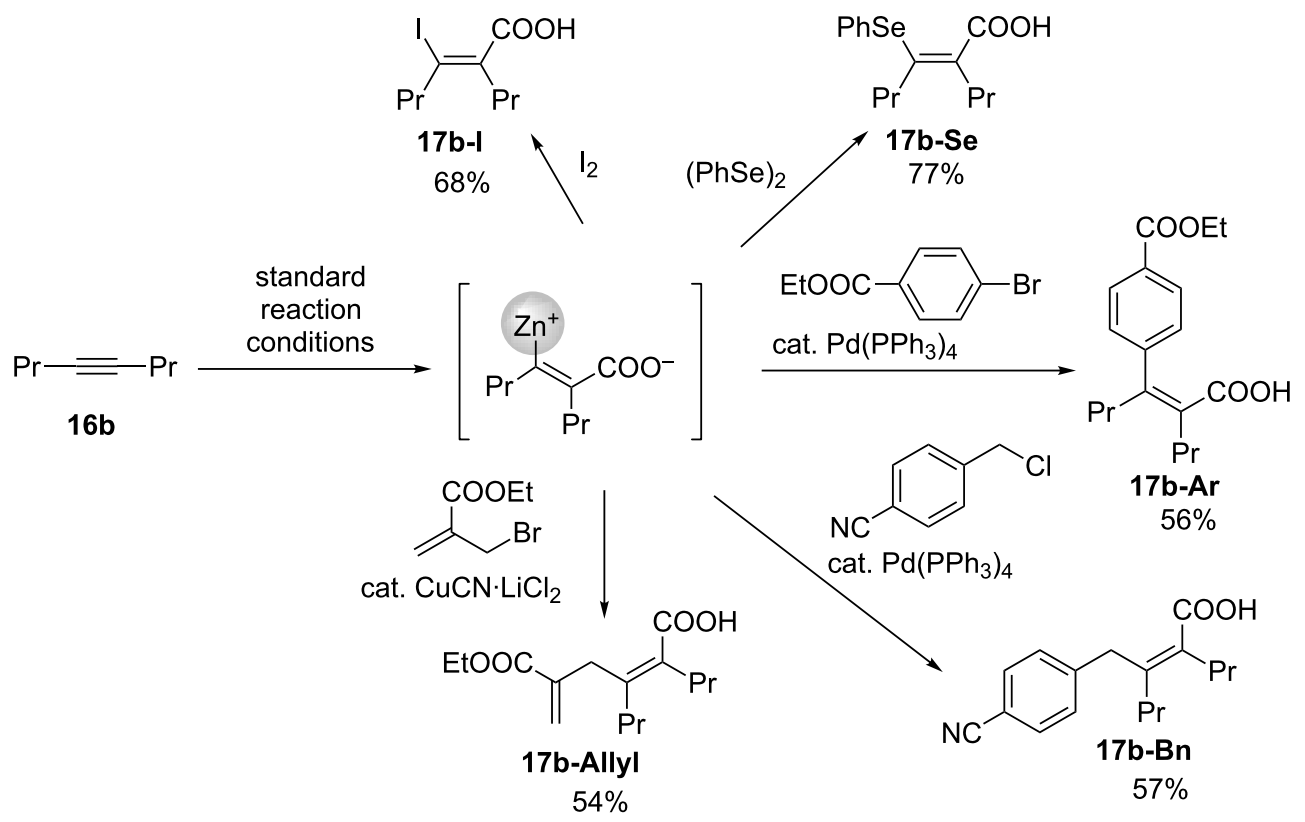




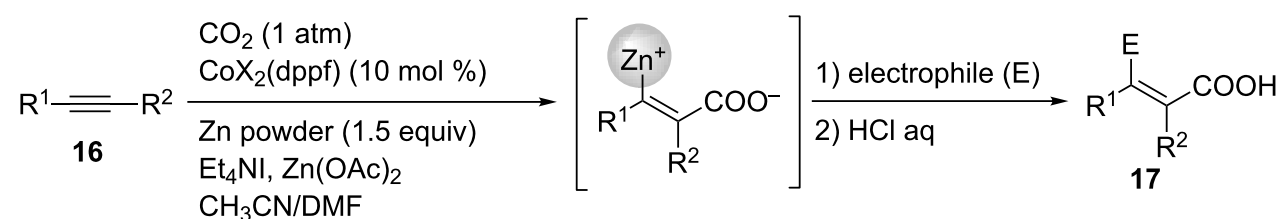<smiles>[2H]/C(C(=O)O)=C(\CCCCC)c1cccc2ccccc12</smiles>

$82 \%(17 c-D)$<smiles>[2H]/C(=C(\CCCCC)C(=O)O)c1cccs1</smiles>

$75 \%(17 d-D)$<smiles>[R]/C(=C(\[2H])C(=O)O)c1ccsc1</smiles>

$52 \%(17 e-D)$<smiles>[2H]/C(C(=O)OC)=C(\CCC)c1ccc(N(C)C)cc1</smiles>

$69 \%(17 f-D)$<smiles>CCCCC(C(=O)O)=C(c1ccc(OC)cc1)c1ccc(OC(C)=O)cc1</smiles>

$73 \%(17 \mathrm{c}-\mathrm{I})$

$48 \%(17 d-A l l y l)$<smiles>CCCCC(C(=O)O)=C(I)c1ccc(OC)cc1</smiles>

$66 \%(17 g-1)$

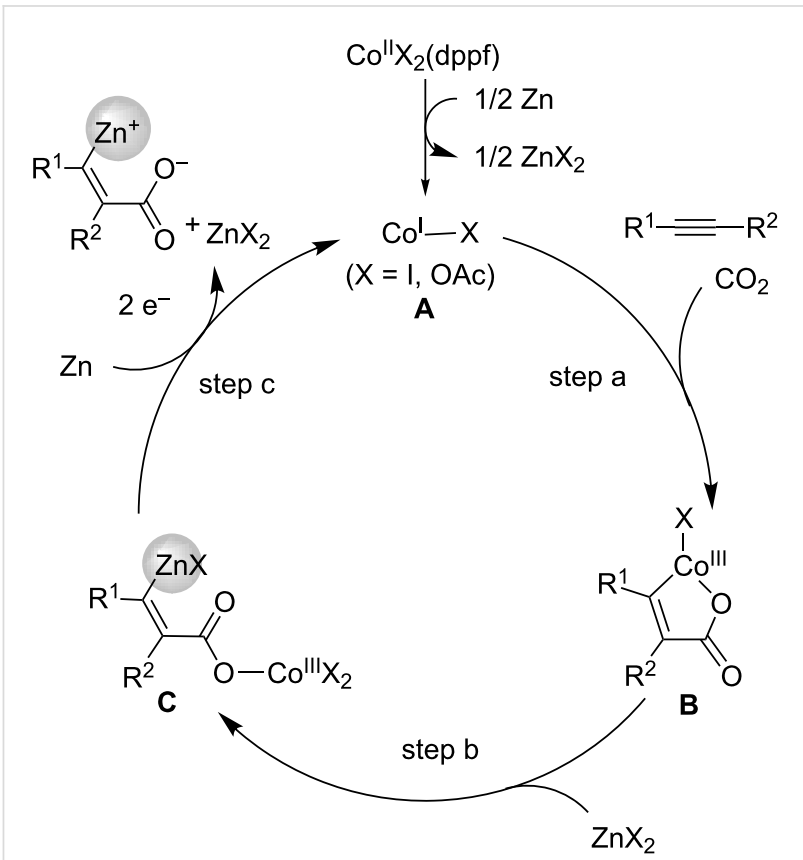

Scheme 17: Plausible reaction mechanism for the Co-catalyzed carboxyzincation of alkynes 16 .

precursor to $\mathrm{Co}(\mathrm{I})$ species $\mathbf{A}$ in the presence of $\mathrm{Zn}$ metal activates the catalytic cycle. Next, the oxidative cyclization of $\mathbf{A}$, alkyne 16, and acrylate $\mathbf{1 8}$ proceeds regioselectively, and cobaltacycle $\mathbf{B}$ is formed (step a) [42]. Then, the insertion of $\mathrm{CO}_{2}$ into the $\mathrm{Co}-\mathrm{C}\left(\mathrm{sp}^{3}\right)$ bond occurs, and the seven-membered $\mathrm{Co}$ intermediate $\mathbf{C}$ is obtained (step b). The transmetalation of $\mathbf{C}$ with the $\mathrm{Zn}$ (II) species proceeds then to afford the alkenylzinc species $\mathbf{D}$ (step c). The subsequent two-electron reduction of $\mathbf{D}$ with $\mathrm{Zn}$ metal occurs, and the alkenylzinc intermediate $\mathbf{E}$ is subsequently obtained, along with the regeneration of $\mathrm{Co}(\mathrm{I})$ species A (step d). After 1,4-migration of zinc in E, product 19 is obtained (step e).

\section{Visible-light-driven hydrocarboxylation of alkynes}

The Use of photoenergy to organic synthesis is of importance, since the highly reactive intermediate can be generated by photochemical reaction such as electron transfer and energy transfer [43-45]. Among them, light-energy-driven $\mathrm{CO}_{2}$ fixation reactions via $\mathrm{C}-\mathrm{C}$ bond formation are promising in terms of mimicking photosynthesis. In 2015, Murakami et al. found the direct carboxylation reaction with $\mathrm{CO}_{2}$ under photo-irradiation reaction conditions [46]. Jamison et al. also reported the synthesis of $\alpha$-amino acid derivatives using amine and $\mathrm{CO}_{2}$ [47]. Iwasawa disclosed the Pd-catalyzed carboxylation of aryl halides using $\mathrm{CO}_{2}$ in the presence of an Ir photo-redox catalyst under visiblelight irradiation conditions [48].

Zhao and $\mathrm{Wu}$ reported the visible-light-driven hydrocarboxylation of alkynes in the presence of a Co catalyst [49]. The reaction of alkynes was carried out using $\mathrm{CoBr}_{2} /$ dcype (dcype $=$ bis(dicyclohexylphosphino)ethane) as catalysts in the presence of $[\operatorname{Ir}(\mathrm{ppy})(\mathrm{dtbpy})]\left(\mathrm{PF}_{6}\right)$ and $\mathrm{iPr}_{2} \mathrm{NEt}$ as photoredox catalyst and a sacrificial reagent, respectively, in acetonitrile under an atmospheric pressure of $\mathrm{CO}_{2}$ (Scheme 20). 1-Phenyl-1-propyne (16n) afforded hydrocarboxylated products as a mixture of 


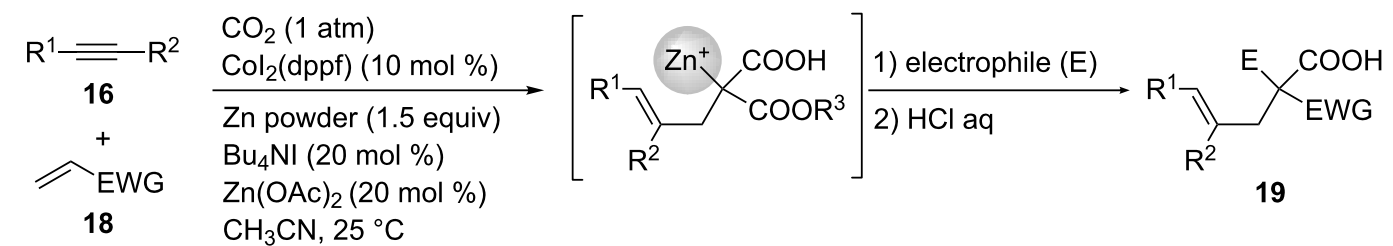

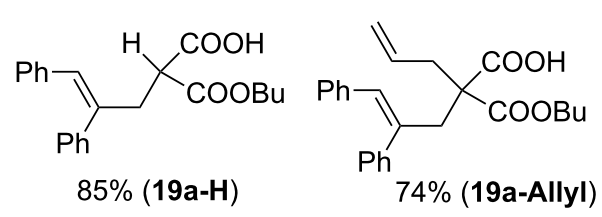<smiles>CCOC(=O)C(C)(C/C(=C/c1ccc(Cl)cc1)c1ccc(Cl)cc1)C(=O)O</smiles><smiles>CCOC(=O)C(C)(C/C(=C/c1cccc(C(F)(F)F)c1)c1cccc(C(F)(F)F)c1)C(=O)O</smiles>

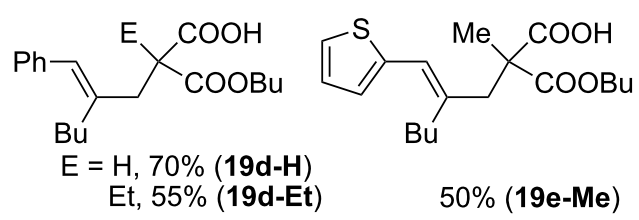<smiles>CCCCC(=CC(OC)OC)CC(C)(C(=O)O)C(=O)OCCC</smiles>
$=\mathrm{H}, 70 \%(19 \mathrm{~d}-\mathrm{H})$ $65 \%$ (19f-Me)<smiles>COC(=O)C(C)(C/C(=C/c1ccccc1)c1ccccc1)C(=O)O</smiles>

47\% (19a-Me-Me)<smiles>CCOC(=O)C(C)(C/C(=C/c1ccccc1)c1ccccc1)C(=O)O</smiles>

$62 \%(19 a-M e-E t)$<smiles>CCOC(=O)C(C)(C/C(=C/c1ccccc1)c1ccccc1)C(=O)O</smiles>

$74 \%$ (19a-Me-Bu)<smiles>CC(=O)C(C/C(=C/c1ccccc1)c1ccccc1)C(=O)O</smiles>

63\% (19a-Me-amide)

Scheme 18: Co-catalyzed four-component coupling of alkynes 16 , acrylates $18, \mathrm{CO}_{2}$, and zinc.

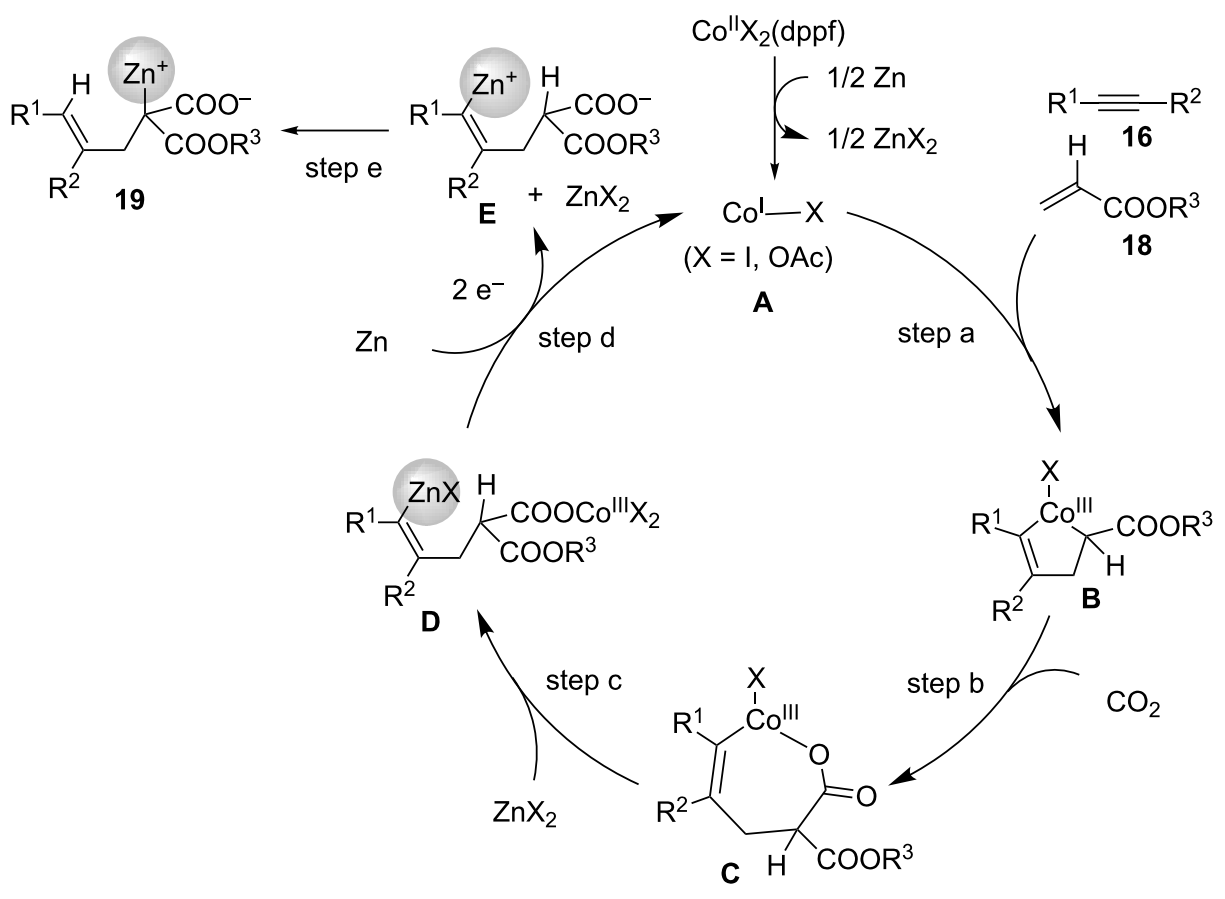

Scheme 19: Proposed reaction mechanism for the Co-catalyzed four-component coupling. 


$$
\begin{aligned}
& \mathrm{CO}_{2} \text { (1 atm) }
\end{aligned}
$$

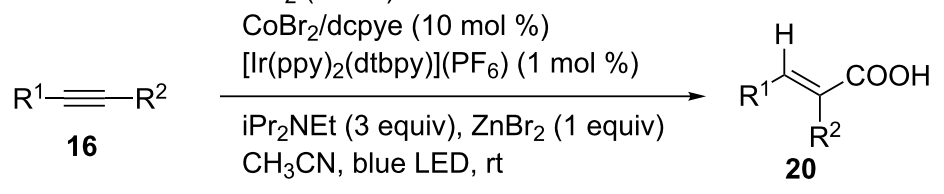

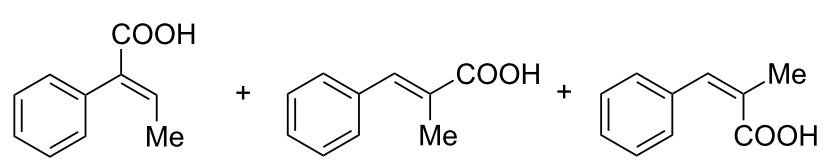

$70 \%\left(20 a^{\prime} / 20 a / 20 a "=1: 3 \cdot 5: 7.1\right)$<smiles>O=C(O)C(C=[PH2])=C[PH2+]</smiles>

$63 \%(20 b)$<smiles>CC/C(=C\C1CC1)C(=O)O</smiles>

$52 \%(20 \mathrm{c})$<smiles>CC(C)(C)/C=C(\Cc1ccccc1)C(=O)O</smiles>

$50 \%(20 d)$

Scheme 20: Visible-light-driven hydrocarboxylation of alkynes.

regio- and stereoisomers. 4-Octyne (16b) afforded the product 20b in good yield. Other unsymmetrical internal alkynes were converted to the corresponding products regioselectively.
The same protocol could be expanded to the synthesis of $\gamma$-hydroxybutenolides by using arylalkynes bearing ortho-esters of the aromatic ring (Scheme 21) [49]. Various alkynes 21 were<smiles>[R]C#Cc1ccccc1OC([R])=O</smiles>

21

\section{$\mathrm{CO}_{2}$ (1 atm)}

$\mathrm{CoBr}_{2} /$ dcpye (10 mol \%)

$\left[\operatorname{lr}(\mathrm{ppy})_{2}(\mathrm{dtbpy})\right]\left(\mathrm{PF}_{6}\right)(1 \mathrm{~mol} \%)$

iPr $2 \mathrm{NEt}$ (3 equiv), $\mathrm{ZnBr}_{2}$ (1 equiv)

$\mathrm{CH}_{3} \mathrm{CN}$, blue LED, rt<smiles>CC(C)CC1=C(c2ccccc2O)C(=O)OC1(C)O</smiles>

$73 \%$ (22b)<smiles>CC(=O)C1=C(c2cc(C(C)C)ccc2O)C(C)(O)OC1=O</smiles>

$70 \%(22 a)$<smiles>CC(=O)c1ccc(O)c(C2=C(C(C)C)C(=O)OC2(C)O)c1</smiles>

$70 \%(22 d)$<smiles>[Y16]C1(O)OC(=O)C(CC(C)C)=C1c1cc(-c2ccccc2)ccc1O</smiles>

$67 \%(22 e)$<smiles>[R]C1=C(c2ccccc2O)C([R])(O)OC1=O</smiles>

22<smiles>CCCCC1=C(c2cc(OC)ccc2O)C(C)(O)OC1=O</smiles>

$50 \%(22 f)$<smiles>CC(=O)CCC1(O)OC(=O)C(C(C)C)=C1c1ccccc1O</smiles>

$71 \%$ (22g) 
converted to the corresponding products in moderate-to-good yields. Notably, ketone (22c) and ester (22d,g) functionalities were tolerated in the reaction. A bulky ester moiety took part in the reaction and the corresponding product $\mathbf{2 2} \mathbf{h}$ was obtained in good yield.

Furthermore, the same group discovered the one-pot synthesis of coumarin derivatives via hydrocarboxylation/alkene isomerization/cyclization reactions (Scheme 22) [49]. A key of the sequential reactions is a use of aromatic alkynes bearing a momo-protected hydroxy group at the ortho position on the aromatic ring (23). The corresponding coumarin derivatives were obtained in moderate-to-good yields. Notably, ketone (24e), ester (24d) moieties were tolerated in the reaction. In addition, 2-quinolones (24f and $\mathbf{2 4 g}$ ) were obtained using alkynes bearing a Boc protected carbamate in place of the MOM protected ether.

Scheme 23 shows a plausible reaction mechanism for these reactions. First, the $\mathrm{Co}(\mathrm{II})$ precursor is reduced to $\mathrm{Co}(\mathrm{I}) \mathbf{A}$ by the aid of an Ir photoredox catalyst and an amine under irradiation. The oxidative cyclization of $\mathbf{A}$ with $\mathbf{2 3}$ and $\mathrm{CO}_{2}$ affords cobaltacycle $\mathbf{B}$ (step a). Next, the protonation of $\mathbf{B}$ affords an intermediate $\mathbf{C}$ (step b). Finally, two-electron reduction of $\mathrm{Co}$ (III) in $\mathbf{C}$ occurs and $\mathrm{Co}(\mathrm{I})$ species $\mathbf{A}$ regenerates (step c). $\mathrm{ZnBr}_{2}$ may facilitate the step. Under the irradiation conditions, an $E$-isomer with aryl moiety can undergo a reversible isomerization to form the corresponding Z-isomer. Acid-mediated cyclization affords a coumarin derivative.

\section{Rhodium catalysts}

\section{Carboxylation of aryl and alkenylboronic esters}

Aryl and alkenylboronic acids or their esters are of interest in organic synthesis because they are commonly used for $\mathrm{C}-\mathrm{C}$ bond-forming reactions such as Pd-catalyzed Suzuki-Miyaura coupling reactions [50-53].

Iwasawa et al. reported the Rh-catalyzed carboxylation of arylboronic esters using $\mathrm{CO}_{2}$ (Scheme 24) [54]. The reaction of 25a was performed using a catalytic amount of $[\mathrm{Rh}(\mathrm{OH})(\mathrm{cod})]_{2}$ and 1,3-bis(diphenylphosphino)propane (dppp) in the presence of $\mathrm{CsF}$ as a base in 1,4-dioxane at $60{ }^{\circ} \mathrm{C}$. Under these reaction conditions, the desired carboxylated product 26a was obtained in $75 \%$ yield. A variety of arylboronic esters $(\mathbf{2 5 b} \mathbf{b}-\mathbf{i})$ were converted into the corresponding carboxylic acids $\mathbf{2 6} \mathbf{b}-\mathbf{i}$ in good-to-high yields. It is noteworthy that ketone, ester, and nitrile functionalities in $\mathbf{2 6 d}$, 26e, and 26f, respectively, were tolerated in the reaction. Sterically hindered substrates could be subjected to the reaction, and $\mathbf{2 6 g}$ was obtained from 25g. Moreover, a substrate having a heteroaromatic ring (25i) was converted into its corresponding carboxylic acid 26i.

Alkenylboronic esters 27 were also converted into the corresponding $\alpha, \beta$-unsaturated carboxylic acids $\mathbf{2 8}$ using $[\mathrm{RhCl}(\mathrm{nbd})]_{2}(\mathrm{nbd}=$ norbornadiene $)$ as a catalytic precursor (Scheme 25) [54]. When an alkyl-substituted substrate was examined, the $p$-methoxy-substituted dppp derivative was found to be the suitable ligand.
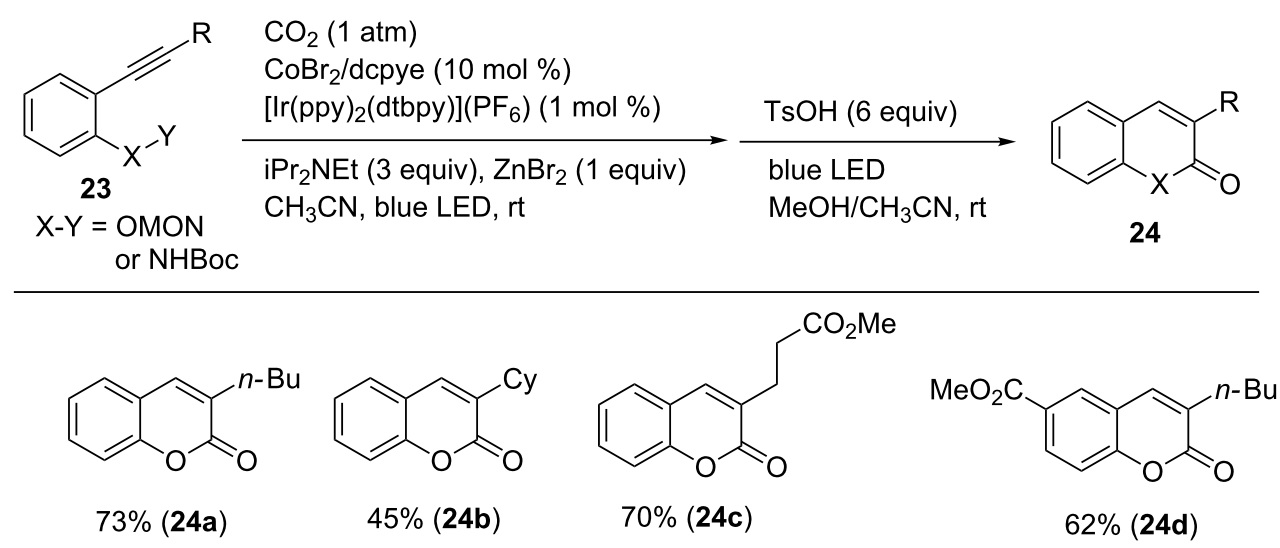<smiles>CCCCc1cc2cc(C(C)=O)ccc2oc1=O</smiles>

$72 \%(24 e)$<smiles>CCCCOc1cc2ccccc2[nH]c1=O</smiles>

$70 \%$ (24f)<smiles>CCCCc1cc2cc(C)ccc2[nH]c1=O</smiles>

$58 \%(24 g)$ 


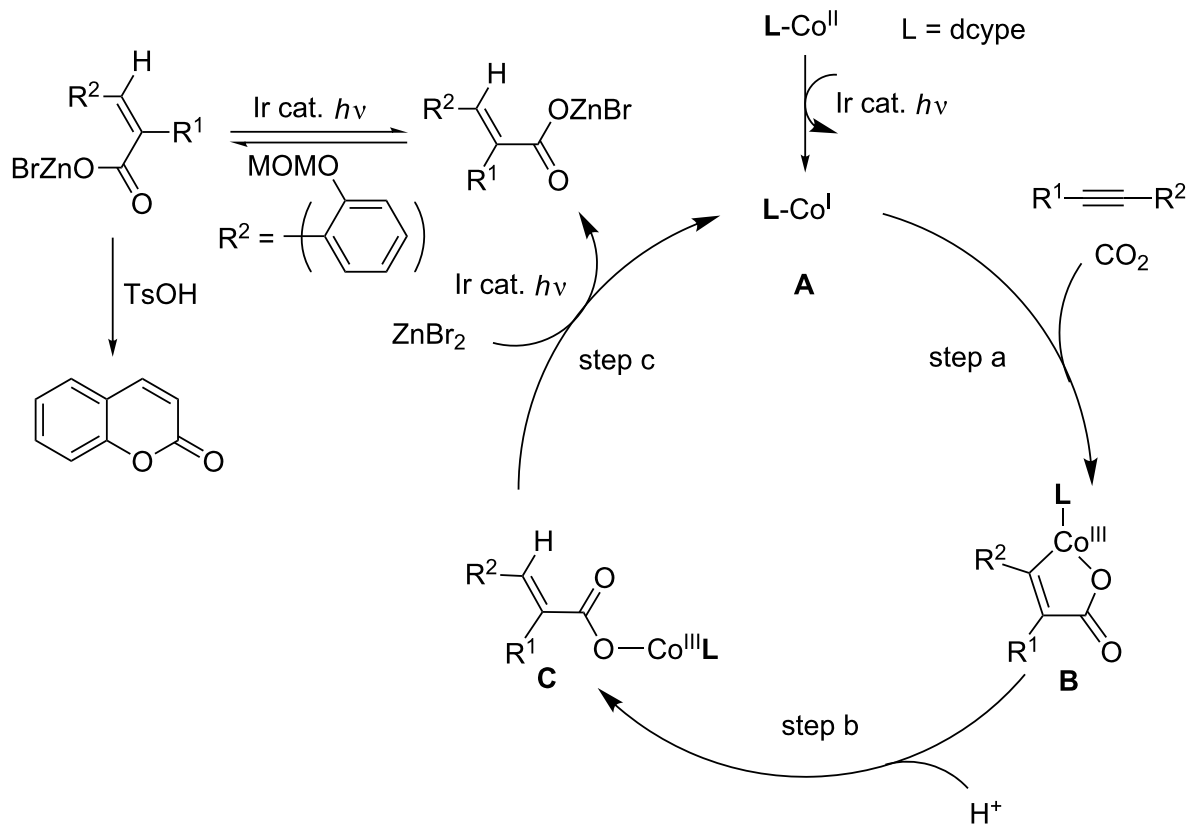

Scheme 23: Proposed reaction mechanism for the Co-catalyzed carboxylative cyclization of ortho-substituted aromatic alkynes.

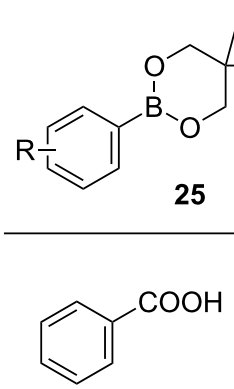

$75 \%$ (26a)

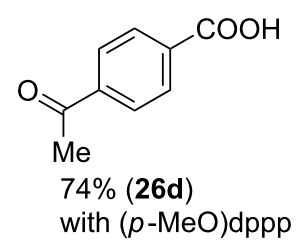<smiles>COc1ccccc1C(=O)O</smiles>

77\% (26g)

with ( $p-\mathrm{MeO}) \mathrm{dppp}$
$\mathrm{CO}_{2}(1 \mathrm{~atm})$

$[\mathrm{Rh}(\mathrm{OH})(\mathrm{cod})]_{2}(3 \mathrm{~mol} \%)$ dppp $(7 \mathrm{~mol} \%)$

$\mathrm{CsF}$ (3 equiv)

1,4-dioxane, $60^{\circ} \mathrm{C}$<smiles></smiles>

26<smiles>COc1ccc(C(=O)O)cc1</smiles><smiles>COC(=O)c1ccc(C(=O)O)cc1</smiles><smiles>N#CCc1ccc(C(=O)O)cc1</smiles>

67\% (26e)

49\% (26f)

with $(p-\mathrm{MeO}) \mathrm{dppp}$

with ( $p-\mathrm{MeO}) \mathrm{dppp}$<smiles>O=C(O)c1ccc2ccccc2c1</smiles>

$82 \%(26 h)$

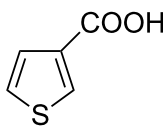

$64 \%(26 i)$

$$
\begin{array}{ll}
\mathrm{Ar}_{2} \mathrm{P} & \mathrm{Ar}=\mathrm{Ph}: \mathrm{dppp} \\
& \mathrm{Ar}=p-\mathrm{MeOC}_{6} \mathrm{H}_{4}:(p-\mathrm{MeO}) \mathrm{dppp}
\end{array}
$$




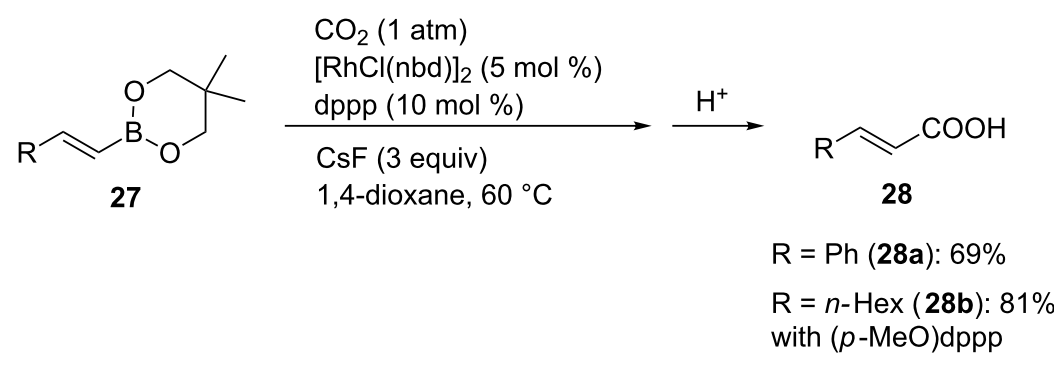

Scheme 25: Rh-catalyzed carboxylation of alkenylboronic esters 27

For this transformation, the reaction mechanism depicted in Scheme 26 was proposed. The catalytic cycle is activated by the generation of aryl-Rh intermediate $\mathbf{A}$ from the reaction of the $\mathrm{Rh}(\mathrm{I})$ species with the corresponding arylboronic ester. Next, the reaction of $\mathbf{A}$ with $\mathrm{CO}_{2}$ proceeds with the concomitant generation of the corresponding carboxylate Rh species $\mathbf{B}$ (step a) Finally, transmetalation between $\mathbf{B}$ and the arylboronic ester affords the product, along with the aryl-Rh intermediate $\mathbf{A}$ (step b)

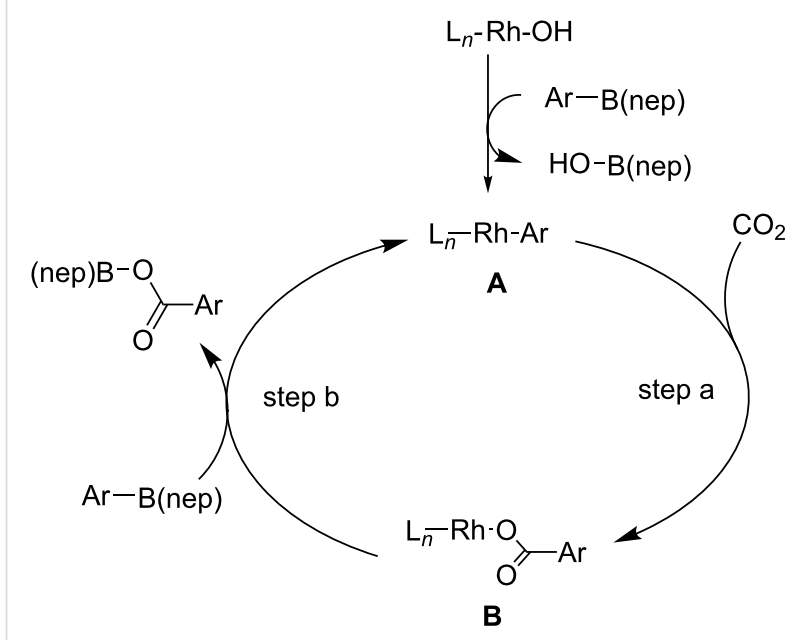

Scheme 26: Plausible reaction mechanism for the Rh-catalyzed carboxylation of arylboronic esters 25.

After this contribution, the Cu-catalyzed carboxylation of aryl and alkenylboronic esters was independently reported by the groups of Iwasawa and How $[55,56]$.

\section{Direct $\mathrm{C}\left(\mathrm{sp}^{2}\right)-\mathrm{H}$ bond carboxylation}

As described above, $\mathrm{C}-\mathrm{H}$ carboxylations with $\mathrm{CO}_{2}$, particularly $\mathrm{C}\left(\mathrm{sp}^{2}\right)-\mathrm{H}$ carboxylation reactions, have attracted much research interest. As a consequence, Nolan [57] and Hou [58] independently reported $\mathrm{Cu}$-catalyzed carboxylations using heteroarenes as substrates, which occur at the relatively acidic $\mathrm{C}-\mathrm{H}$ bond.
Regarding $\mathrm{Rh}$ as the catalyst, Iwasawa et al. first reported a rhodium-catalyzed chelation-assisted $\mathrm{C}\left(\mathrm{sp}^{2}\right)-\mathrm{H}$ carboxylation using methylaluminum as a reducing reagent (Scheme 27) [59]. Subsequently, the reaction of 2-phenylpyridine (29a) was performed using $\mathrm{AlMe}_{2}(\mathrm{OMe})$ in DMA at $70{ }^{\circ} \mathrm{C}$. Employing $[\mathrm{RhCl}(\text { coe })]_{2}($ coe $=$ cyclooctene $)$ and $\mathrm{P}(\mathrm{Mes})_{3}\left(\left(\mathrm{P}(\mathrm{Mes})_{3}=\right.\right.$ tris(2,4,6-trimethylphenyl)phosphine) as the catalyst, the carboxylated product 30a was obtained in $67 \%$ yield, along with the formation of a methylated byproduct 31a. Other phosphine ligands such as $\mathrm{PPh}_{3}, \mathrm{P}(t-\mathrm{Bu})_{3}$, and $\mathrm{PCy}_{3}$ afforded the product in low-to-good yields.

Under the optimal reaction conditions using $\mathrm{PCy}_{3}$ as the ligand, various 2-pyridylarenes 29 were converted into the corresponding products 30 (Scheme 28). Substrates bearing either electrondonating or electron-withdrawing substituents at the aryl ring afforded the corresponding products. Interestingly, a terminal alkenyl group remained intact after the reaction (30d). Furthermore, substrates bearing naphthyl or furyl rings were carboxylated, and the corresponding products, 30e and 30f, respectively, were obtained in good yields.

A plausible reaction mechanism for this Rh-catalyzed chelationassisted C( $\left.\mathrm{sp}^{2}\right)-\mathrm{H}$ bond carboxylation is shown in Scheme 29. First, a low-valent methyl-Rh(I) species $\mathbf{A}$ is generated by transmetalation. Secondly, a pyridine ring in the substrate coordinates to the $\mathrm{Rh}$ center, which prompts the cleavage of the adjacent $\mathrm{C}-\mathrm{H}$ bond, affording $\mathrm{Rh}(\mathrm{III})$ species B (step a). Subsequently, the reductive elimination of methane from $\mathbf{B}$ affords the low-valent $\mathrm{Rh}(\mathrm{I})$ species $\mathbf{C}$. Then, $\mathrm{C}-\mathrm{C}$ bond formation with $\mathrm{CO}_{2}$ proceeds, and $\mathrm{Rh}$ carboxylate $\mathbf{D}$ is formed. Finally, the carboxylated product is obtained by the transmetalation between $\mathbf{D}$ and $\mathrm{AlMe}_{2}(\mathrm{OMe})$, and methyl-Rh(I) $\mathbf{A}$ is regenerated.

Later, Iwasawa et al. achieved the Rh-catalyzed direct carboxylation of arenes without any directing group (Scheme 30) $[60,61]$. The reactions proceeded using a catalytic amount of $\mathrm{Rh}$ complex bearing dcype (dcype $=1,2$-bis(dicyclohexylphosphino)ethane) as the ligand and $\mathrm{AlMe}_{2}(\mathrm{OEt})$ as a reducing agent 


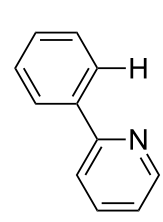

$29 a$

\section{$\mathrm{CO}_{2}$ (1 atm)}

$\mathrm{RhCl}(\mathrm{coe})]_{2}(5 \mathrm{~mol} \%)$

phosphine (12 mol \%)

$\mathrm{AlMe}_{2}(\mathrm{OMe})$ (2 equiv)

DMA, $70^{\circ} \mathrm{C}$
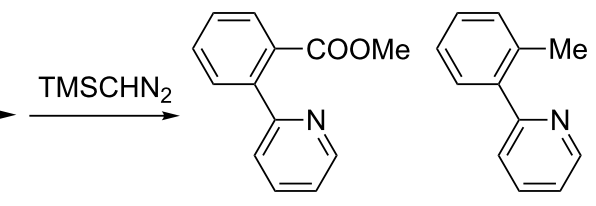

30 a yield $(\%) \quad 31$ a yield $(\%)$

$\begin{array}{lll}\mathrm{P}(\mathrm{Mes})_{3} & 67 & 13\end{array}$

$\begin{array}{lll}\mathrm{PPh}_{3} & 5 & 22\end{array}$

$\mathrm{P}(t-\mathrm{Bu})_{3} \quad 35 \quad 17$

$\mathrm{PCy}_{3} \quad 73 \quad 21$

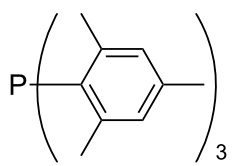

$\mathrm{P}(\mathrm{Mes})_{3}$

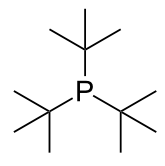

$\mathrm{P}(t-\mathrm{Bu})_{3}$

Scheme 27: Ligand effect on the Rh-catalyzed carboxylation of 2-phenylpyridine 29a.

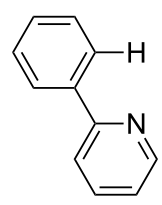

$\mathrm{CO}_{2}(1 \mathrm{~atm})$

$\mathrm{RhCl}(\mathrm{coe})]_{2}(5 \mathrm{~mol} \%)$

$\mathrm{PCy}_{3}(12 \mathrm{~mol} \%)$

$\mathrm{AlMe}_{2}(\mathrm{OMe})$ ( 2 equiv)

DMA, $70{ }^{\circ} \mathrm{C}$

29

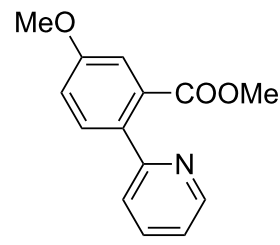

$75 \%(30 b)$

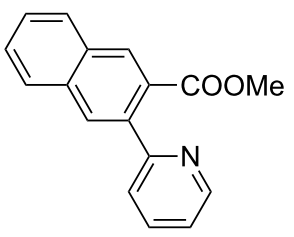

$66 \%(30 \mathrm{e})$

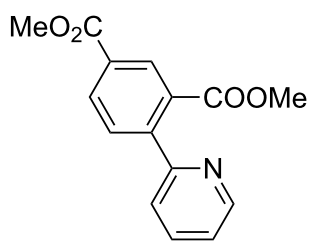

$51 \%(30 c)$

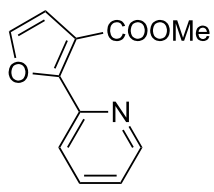

$69 \%(30 f)$

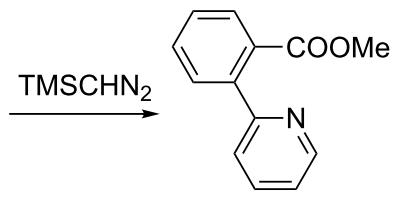

30

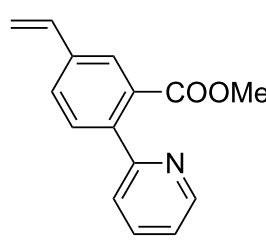

$68 \%(30 d)$

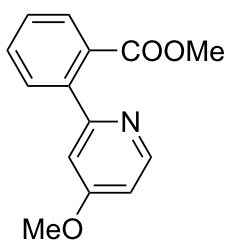

$73 \%(30 \mathrm{~g})$

Scheme 28: Rh-catalyzed chelation-assisted $\mathrm{C}\left(\mathrm{sp}^{2}\right)-\mathrm{H}$ bond carboxylation with $\mathrm{CO}_{2}$.

in a mixture of DMA and 1,1,3,3-tetramethylurea (TMU) as a solvent. Under the reaction conditions, benzene (32a) was converted into benzoic acid (33a, TON: 37$)$ at $85{ }^{\circ} \mathrm{C}$. The monosubstituted arenes such as toluene (32b), fluorobenzene (32c), and trifluoromethylbenzene (32d) afforded the corresponding carboxylic acids 33b, 33c , and 33d in good TON. o-Xylene yielded its corresponding mixture of carboxylic acids $33 \mathbf{e}$. When 1,3-bis(trifluoromethyl)benzene (32f) was used as the substrate at $145^{\circ} \mathrm{C}$, the corresponding carboxylic acid $\mathbf{3 3 f}$ was site-selectively obtained in good TON. Benzofuran (32h) and indole (32i) also gave the carboxylic acids, which were isolated as their methyl esters.

$\mathrm{Li}$ and co-workers reported the Rh-catalyzed site-selective $\mathrm{C}\left(\mathrm{sp}^{2}\right)-\mathrm{H}$ carboxylation reaction using 2-arylphenols as the substrates (Scheme 31) [62]. The desired reactions proceeded using 


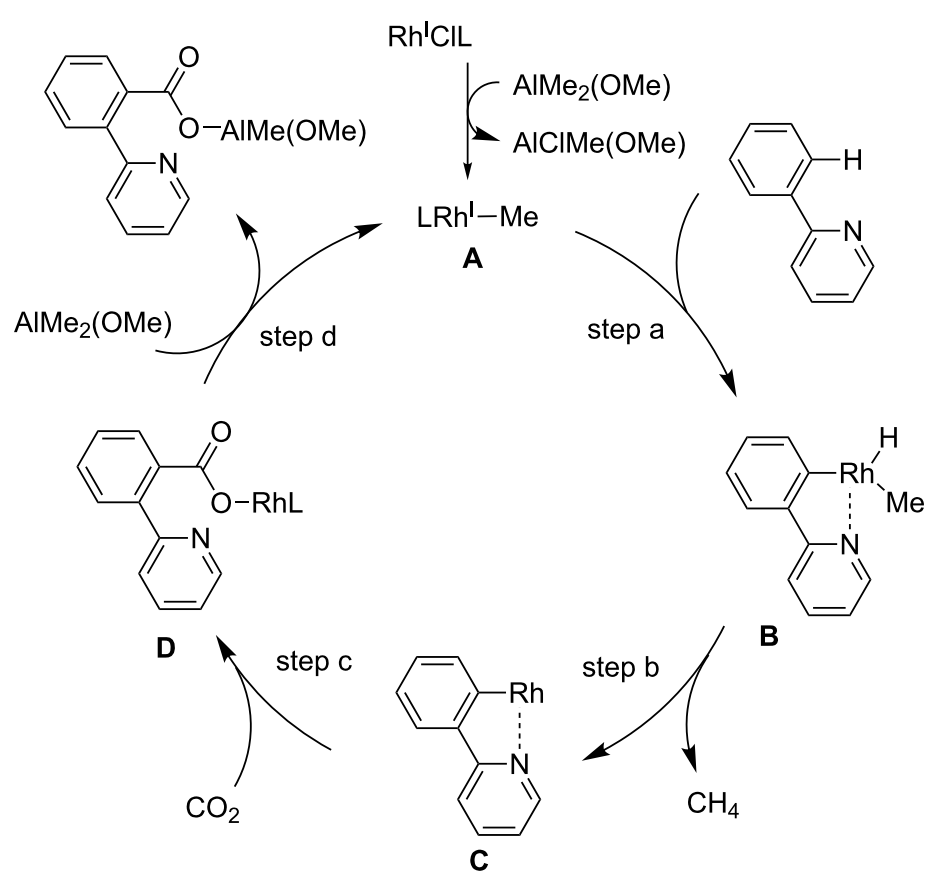

Scheme 29: Reaction mechanism for the Rh-catalyzed C(sp $\left.{ }^{2}\right)-\mathrm{H}$ carboxylation of 2-pyridylarenes 29.

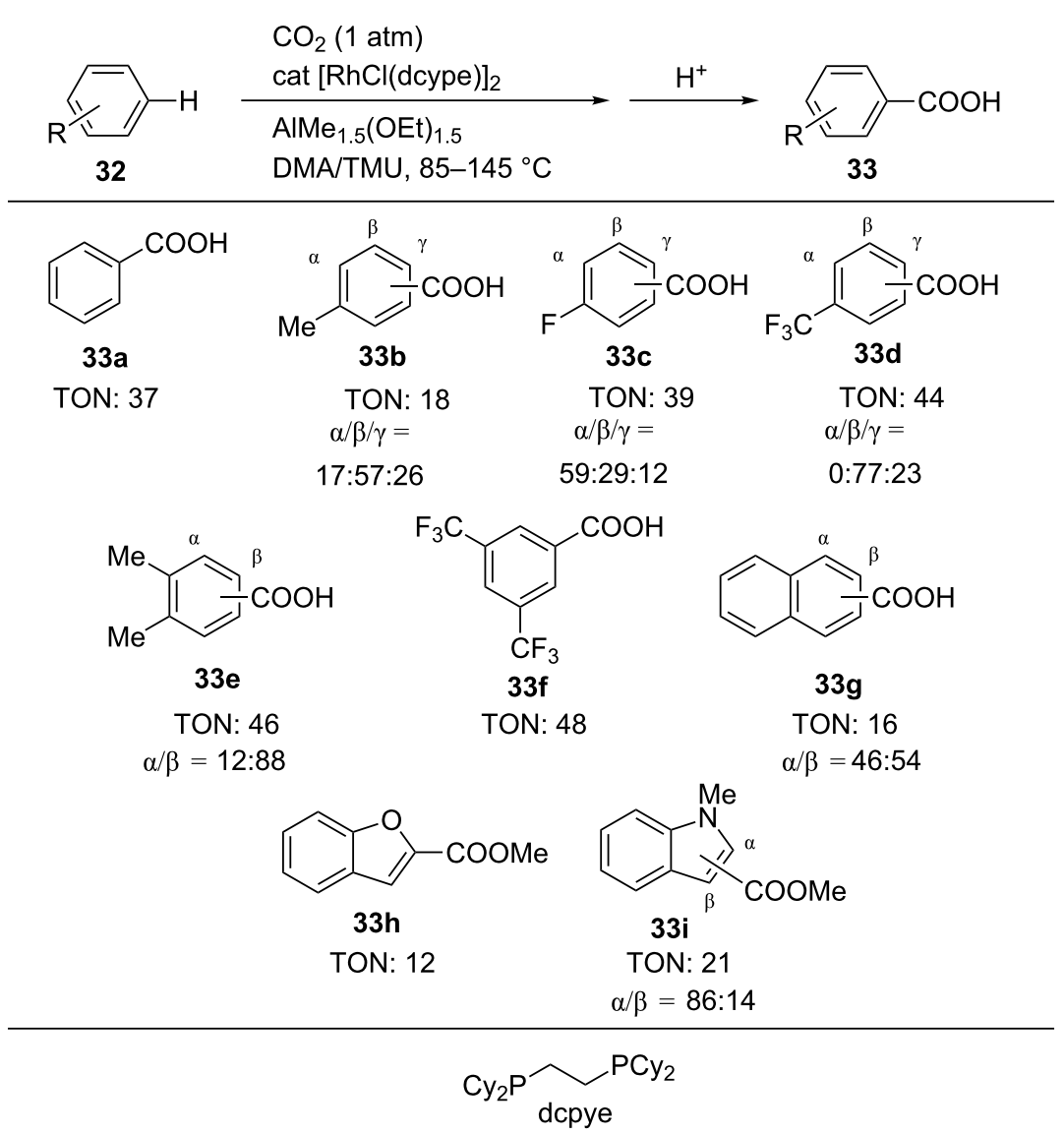

Scheme 30: Carboxylation of $\mathrm{C}\left(\mathrm{sp}^{2}\right)-\mathrm{H}$ bond with $\mathrm{CO}_{2}$. 
<smiles>Oc1cc[se]c1C1#[R1]=CC=C1</smiles>

34

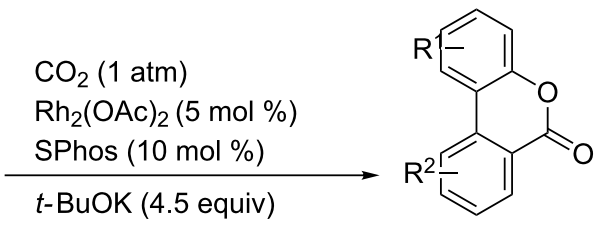

35<smiles>O=c1oc2ccccc2c2ccccc12</smiles>

95\% (35a)<smiles>COc1ccc2c(=O)oc3ccccc3c2c1</smiles>

$96 \%$ (35b)<smiles>Cc1ccc2oc(=O)c3ccccc3c2c1</smiles>

$97 \%$ (35c)<smiles>Cc1cccc2oc(=O)c3ccccc3c12</smiles>

$66 \%$ (35d) with $\mathrm{PCy}_{3}$ at $120^{\circ} \mathrm{C}$<smiles>O=c1oc2cc(F)ccc2c2ccccc12</smiles><smiles>O=c1oc2ccc3ccccc3c2c2ccccc12</smiles>

$87 \%(35 e)$ with $\mathrm{PCy}_{3}$ at $100{ }^{\circ} \mathrm{C}$

$71 \%(35 f)$ at $120{ }^{\circ} \mathrm{C}$<smiles>COc1ccc2oc(=O)c3ccc(OC)cc3c2c1</smiles>

95\% (35g) at $100{ }^{\circ} \mathrm{C}$
$\mathrm{MeO}$<smiles>O=c1oc2ccc(I)cc2c2ccc(C(F)(F)F)cc12</smiles>

$89 \%$ (35h) at $120^{\circ} \mathrm{C}$

SPhos

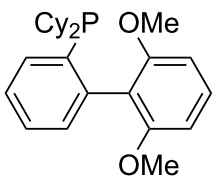

Scheme 31: Carboxylation of $\mathrm{C}\left(\mathrm{sp}^{2}\right)-\mathrm{H}$ bond with $\mathrm{CO}_{2}$.

a $\mathrm{Rh}_{2}(\mathrm{OAc})_{4} / \mathrm{SPhos}$ catalyst system and $t$-BuOK as a base in DMF. Under the optimal reaction conditions, the reaction with 2-phenylphenol (34a) afforded dibenzopyranone (35a) in 95\% yield. Other substituted 2-arylphenol derivatives $(\mathbf{3 4 b}-\mathbf{h})$ were converted to the corresponding dibenzopyranones $(\mathbf{3 5 b}-\mathbf{h})$ in good-to-high yields. Notably, sterically hindered substrates (34d and 34f) were allowed by elevating the reaction temperature.

A plausible reaction mechanism is shown in Scheme 32. First, a phenoxide 34' generated by the reaction of 2-arylphenol with $t$ - $\mathrm{BuOK}$ reacts with a $\mathrm{Rh}$ complex $\mathbf{A}$ to generate a $\mathrm{Rh}$ complex B (step a). Then, chelation-assisted $\mathrm{C}-\mathrm{H}$ bond activation proceeds to generate a rhodacycle $\mathbf{C}$ (step b). The reaction of $\mathbf{C}$ with $\mathrm{CO}_{2}$ affords an eight-membered rhodacycle intermediate $\mathbf{D}$ (step c). Next, $\mathbf{D}$ is converted to the corresponding rhodium complex E by ligand exchange with KOAc (step d). Possibly another ligand exchange between $\mathbf{E}$ and KOAc regenerates the Rh complex A (step e). The desired product (35) is obtained after lactonization.

\section{Hydrocarboxylation of arylalkenes}

Hydrocarboxylation is an essential carboxylation reaction. To date, transition-metal-catalyzed hydrocarboxylation reactions using alkynes [63-66], alkenes [67,68], allenes [69-71] and 1,3dienes $[72,73]$ have been reported. In this regard, Mikami et al. reported the Rh-catalyzed hydrocarboxylation of styrene derivatives depicted in Scheme 33 [74]. The desired reaction proceeded using $[\mathrm{RhCl}(\mathrm{cod})]_{2}$ as a catalyst and $\mathrm{Et}_{2} \mathrm{Zn}$ as a reducing agent in $\mathrm{DMF}$ at $0{ }^{\circ} \mathrm{C}$. As a result, diverse styrene derivatives 36a-f bearing an electron-withdrawing group were converted into their corresponding carboxylic acids $\mathbf{3 7 a}-\mathbf{f}$ in moderate-to-high yields. Notably, the ester, ketone, and amide functionalities of $\mathbf{3 7 a}, \mathbf{3 7 c}$, and $\mathbf{3 7 d}$, respectively, were toler- 


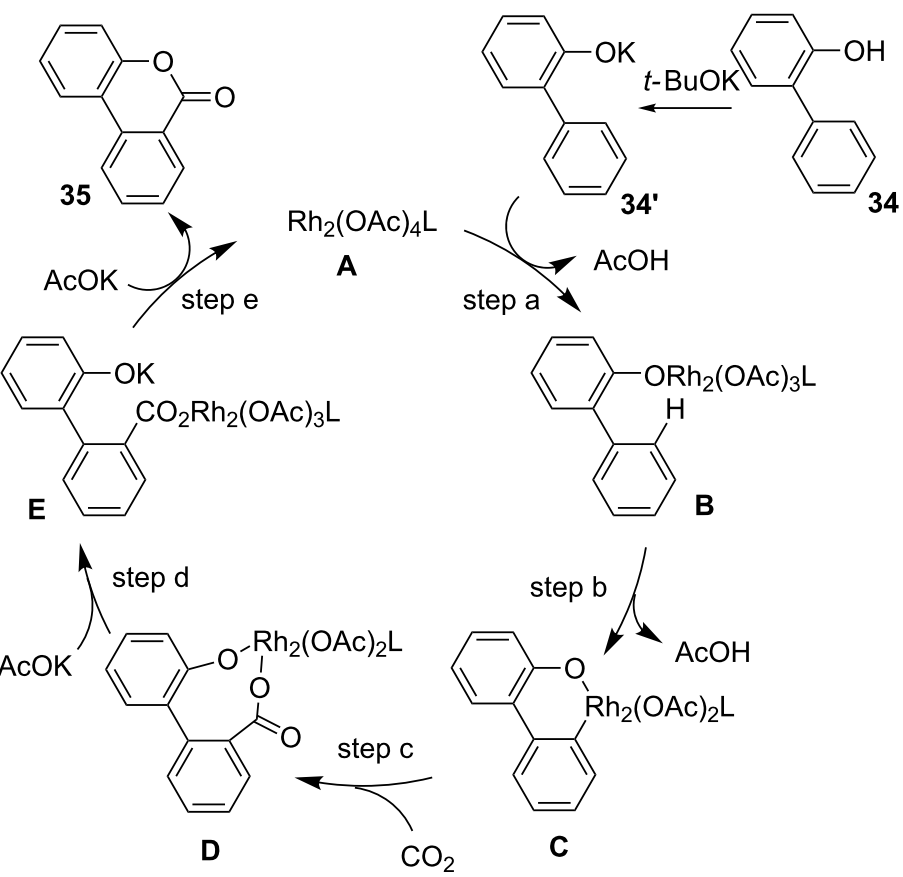

Scheme 32: Reaction mechanism for the Rh-catalyzed C(sp2)-H carboxylation of 2-arylphenols 34 .
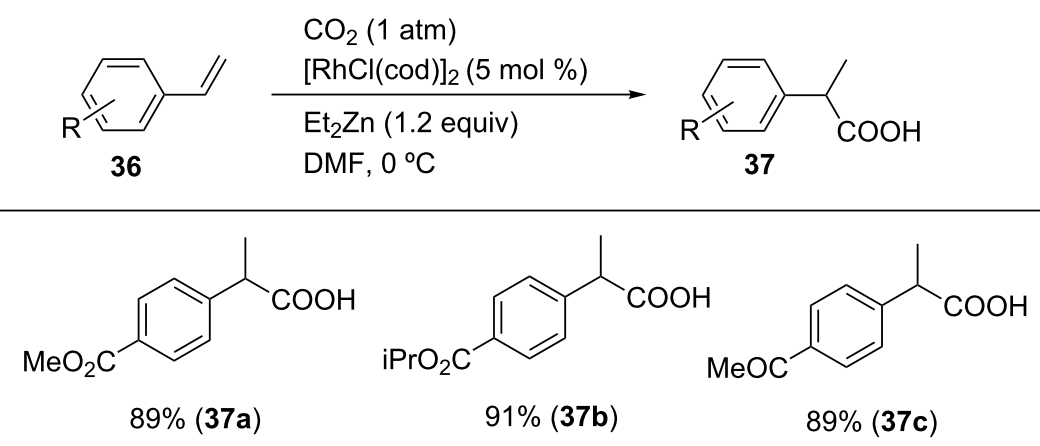<smiles>CCOC(=O)c1ccc(C(C)C(=O)O)cc1</smiles>

$59 \%(37 d)$<smiles>CCOC(=O)c1ccccc1C(C)C(=O)O</smiles>

$63 \%(37 e)$<smiles>CC(=O)c1ccccc1C(C)C(=O)O</smiles>

$73 \%$ (37f)

Scheme 33: Hydrocarboxylation of styrene derivatives with $\mathrm{CO}_{2}$.

ated in the reaction. However, substrates such as 4-methoxystyrene or styrene did not yield the desired products.

The same Rh-catalytic system proved to be applicable to the carboxylation of $\alpha, \beta$-unsaturated esters 38 (Scheme 34). A variety of substrates $\mathbf{3 8 a}-\mathbf{f}$, including those containing an electron-donating substituent or benzyl-substituted esters, were converted into their corresponding products 39a-f in good-to-high yields.
Notably, the asymmetric hydrocarboxylation was archived by using a chiral bisphosphine as a ligand (Scheme 35).

Scheme 36 illustrates a plausible reaction mechanism for this transformation. First, transmetalation between the $\mathrm{Rh}(\mathrm{I})$ and $\mathrm{Zn}$ reagents generates ethyl-Rh(I) species $\mathbf{A}$, from which $\beta$-hydrogen elimination occurs to yield the hydride-Rh intermediate $\mathbf{B}$ (step a). Subsequently, the hydrorhodation of the $\mathrm{C}-\mathrm{C}$ double bond occurs, affording an 

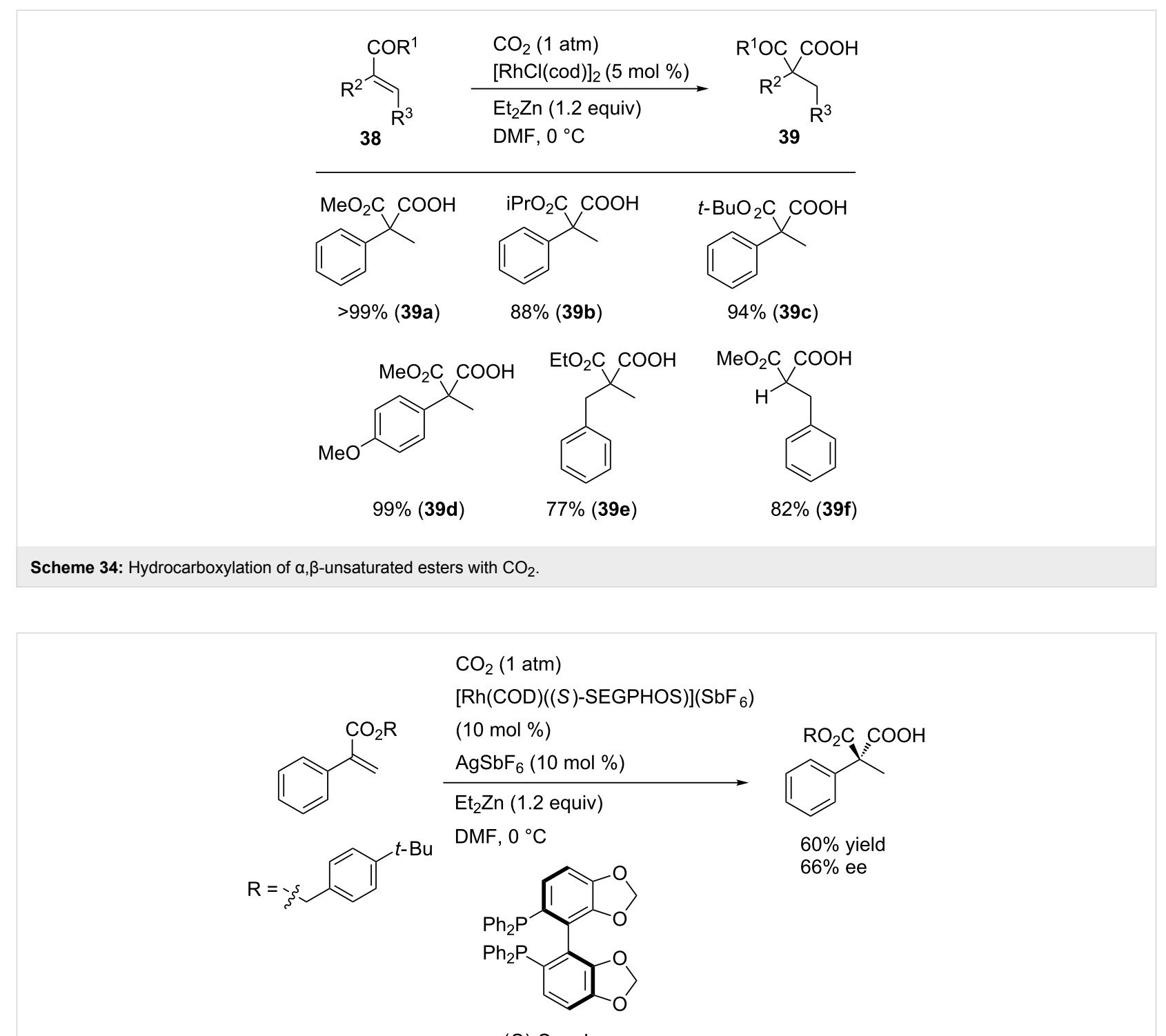

(S)-Segphos

Scheme 35: Asymmetric hydrocarboxylation of $\alpha, \beta$-unsaturated esters with $\mathrm{CO}_{2}$.

alkyl-Rh(I) species $\mathbf{C}$ (step b). Then, $\mathrm{C}-\mathrm{C}$ bond formation with $\mathrm{CO}_{2}$ proceeds to give $\mathrm{Rh}$ carboxylate $\mathbf{D}$ (step c) Finally, the carboxylated product is obtained by the transmetalation between $\mathbf{D}$ and $\mathrm{Et}_{2} \mathrm{Zn}$, with the concomitant regeneration of ethyl-Rh(I) A (step d).

\section{Visible light-driven hydrocarboxylation of alkenes}

Iwasawa et al. reported the Rh-catalyzed hydrocarboxylation of alkenes driven by visible-light irradiation conditions in the presence of a photoredox catalyst (Scheme 37) [75]. A model reaction using 4-cyanostyrene (40a) was carried out using iPrNEt $_{2}$ as a sacrificial electron donor in the presence of $\left[\mathrm{Ru}(\mathrm{bpy})_{3}\right]\left(\mathrm{PF}_{6}\right)_{2}$ as a photoredox catalyst under visible-light irradiation $(425 \mathrm{~nm})$. Employing $\mathrm{Rh}\left(\mathrm{PPh}_{3}\right)_{3} \mathrm{H}$ as a catalyst, the desired hydrocarboxylated product 41a was obtained in 33\% yield along with the formation of reduced product $42 \mathrm{a}$. $\mathrm{Rh}\left(\mathrm{PPh}_{3}\right)_{3} \mathrm{Cl}$ and $\left[\mathrm{Rh}\left(\mathrm{PPh}_{3}\right)_{2} \mathrm{Cl}\right]_{2}$ were not efficient while a use of $\left[\mathrm{Rh}\left(\mathrm{P}\left(4-\mathrm{CF}_{3} \mathrm{C}_{6} \mathrm{H}_{4}\right)_{3}\right)_{2} \mathrm{Cl}\right]_{2}$ afforded $41 \mathrm{a}$ in $54 \%$ yield. Finally, an addition of $\mathrm{Cs}_{2} \mathrm{CO}_{3}$ dramatically reduced the byproduct and 41a was obtained in $67 \%$ yield.

Under the optimal reaction conditions, several substrates were examined and the corresponding hydrocarboxylated products were obtained in moderate yields (Scheme 38).

\section{[2 + 2 + 2] Cycloaddition of diynes with $\mathrm{CO}_{2}$}

The $[2+2+2]$ cycloaddition of diynes with $\mathrm{CO}_{2}$ is an important reaction in the field of $\mathrm{CO}_{2}$ fixation. In these reactions, 

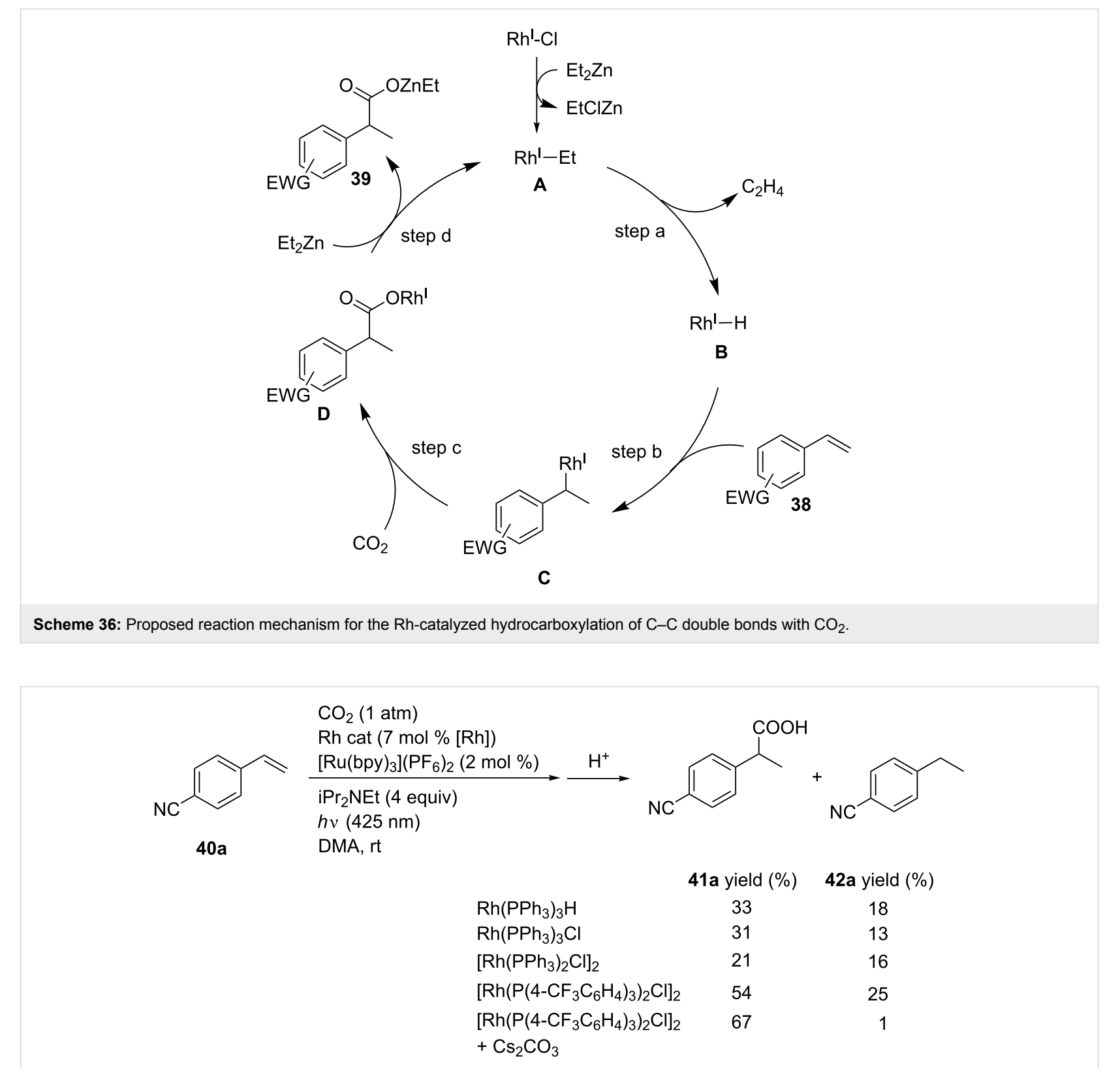

Scheme 37: Visible-light-driven hydrocarboxylation with $\mathrm{CO}_{2}$.

cyclic esters such as pyrones can be obtained, which are classically catalyzed by Ni complexes [76-78]. Tanaka et al. reported that a Rh complex with a suitable bidentate ligand was an efficient catalyst for the $[2+2+2]$ cycloaddition reaction (Scheme 39) [79]. The reaction of 43a was performed using $20 \mathrm{~mol} \%\left[\mathrm{Rh}(\operatorname{cod})_{2}\right] \mathrm{BF}_{4}$ and a bidentate phosphine in 1,2dichloroethane at room temperature. Prior to the addition of 43a, the mixture of $\left[\mathrm{Rh}(\operatorname{cod})_{2}\right] \mathrm{BF}_{4}$ and phosphine was stirred for $30 \mathrm{~min}$. Then, 43a was added dropwise to the mixture over $10 \mathrm{~min}$, and the resulting reaction mixture was further stirred for $16 \mathrm{~h}$. As ligands, SEGPHOS, BIPHEP, and DPPF were ineffective, but BINAP and $\mathrm{H}_{8}$-BINAP afforded the product 44a in moderate yields. Notably, the addition of 43a over $120 \mathrm{~min} \mathrm{im-}$ proved the yield even at low catalyst loadings ( $5 \mathrm{~mol} \%$ ). A high (94\%) yield was eventually obtained by reducing the prestirring time to $5 \mathrm{~min}$.

A variety of diynes having different tether units $(\mathbf{4 3 a} \mathbf{a}-\mathbf{g})$ were converted into the corresponding pyrones $\mathbf{4 4 a -} \mathbf{g}$ in good-tohigh yields within $1 \mathrm{~h}$ (Scheme 40). Ester, ketone, and hydroxy groups were tolerated in the reaction. In the case of an unsymmetrical diyne bearing methyl and isopropyl groups (43g), a mixture of regioisomers $\mathbf{4 4} \mathbf{g}+\mathbf{4 4} \mathrm{g}^{\prime}$ was obtained in high yield with high regioselectivity. 


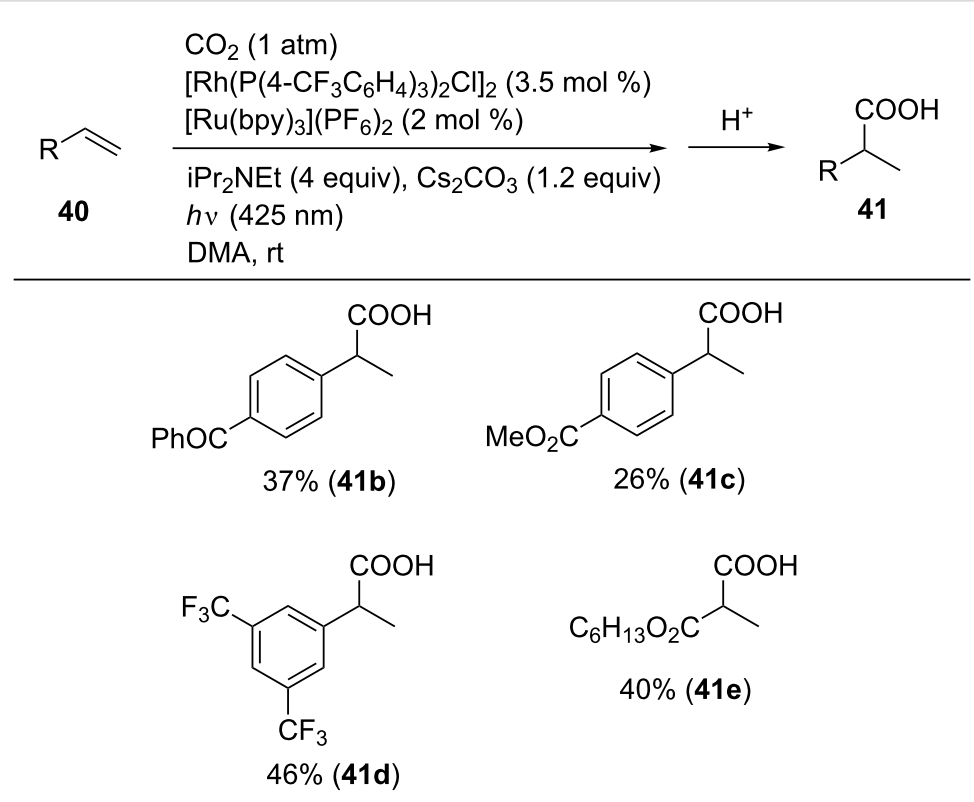

Scheme 38: Visible-light-driven Rh-catalyzed hydrocarboxylation of $\mathrm{C}-\mathrm{C}$ double bonds with $\mathrm{CO}_{2}$.

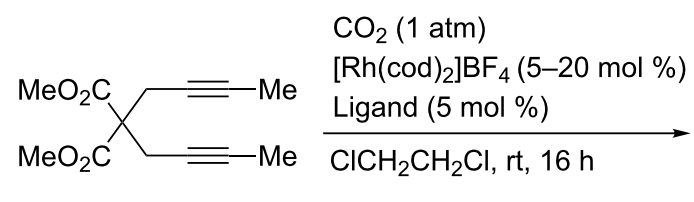

$43 a$

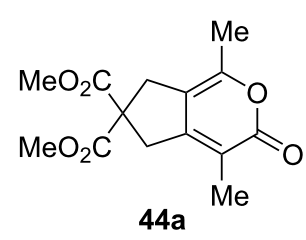

$44 a$

$\begin{array}{lrrcr}\text { ligand } & \begin{array}{c}\text { loading } \\ (\mathrm{mol} \%)\end{array} & \begin{array}{r}\text { prestirring } \\ \text { time }(\mathrm{min})\end{array} & \begin{array}{l}\text { addition } \\ \text { time }(\mathrm{min})\end{array} & \begin{array}{l}\text { yield } \\ (\%)\end{array} \\ \text { SEGPHOS } & 20 & 30 & 10 & 19 \\ \text { BIPHEP } & 20 & 30 & 10 & 9 \\ \text { DPPF } & 20 & 30 & 10 & 25 \\ \text { BINAP } & 20 & 30 & 10 & 41 \\ \mathrm{H}_{8} \text {-BINAP } & 20 & 30 & 10 & 48 \\ \mathrm{H}_{8} \text {-BINAP } & 5 & 30 & 10 & 18 \\ \mathrm{H}_{8} \text {-BINAP } & 5 & 30 & 120 & 78 \\ \mathrm{H}_{8} \text {-BINAP } & 5 & 5 & 120 & 94\end{array}$<smiles>Pc1ccc2c(c1-c1c(P)ccc3c1OCO3)OCO2</smiles>

SEGPHOS<smiles>O=[PH](c1ccccc1)c1ccccc1-c1ccccc1P</smiles>

BIPHEP<smiles>c1ccc(-c2ccc3ccccc3c2-c2cccc3ccc(-c4ccccc4)c(-c4ccccc4)c23)cc1</smiles>

BINAP<smiles>Pc1cccc(-c2ccccc2)c1P</smiles>

$\mathrm{H}_{8}$-BINAP

Scheme 39: Optimization of reaction conditions on the Rh-catalyzed [2 + 2+2] cycloaddition of diyne $42 \mathrm{a}$ and $\mathrm{CO}_{2}$.

For this transformation, the reaction pathways depicted in Scheme 41 can be envisaged. The $\mathrm{Rh}(\mathrm{I})$ species $\mathbf{A}$ reacts with a diyne to afford rhodacycle $\mathbf{B}$ (step a). Then, the reaction of $\mathbf{B}$ with $\mathrm{CO}_{2}$ produces the seven-membered rhodium intermediate
C (step b), from which reductive elimination occurs to yield its corresponding pyrone and the $\mathrm{Rh}(\mathrm{I})$ species $\mathbf{A}$ (step c). Alternatively, the oxidative cyclization of $\mathbf{A}$ proceeds as one of the $\mathrm{C}-\mathrm{C}$ triple bonds of the diyne and $\mathrm{CO}_{2}$ react regioselectively, 


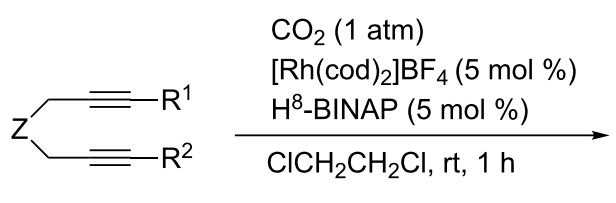

43

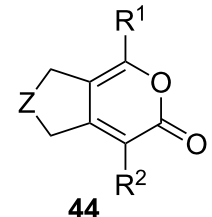

44

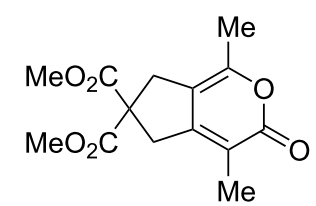

$90 \%(44 a)$<smiles></smiles>

$62 \%(44 b)$<smiles>[R17]C1(C(=O)c2ccccc2)Cc2c(C)oc(=O)c(C)c2C1</smiles>

$70 \%(44 c)$<smiles></smiles>

$>99 \%(44 d)$<smiles>Cc1oc(=O)c([N+](=O)[O-])c2c1CC(O)(CO)C2</smiles>

$46 \%(44 \mathrm{e})$<smiles></smiles>

$78 \%(44 f)$

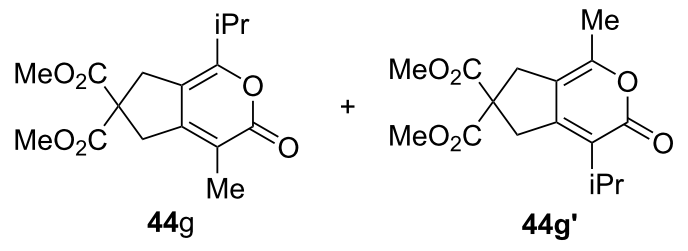

$4 \mathbf{4} \mathbf{g}+\mathbf{4 4} \mathbf{g}^{\prime} \quad \mathbf{8 1 \%}(96: 4)$

Scheme 40: $[2+2+2]$ Cycloaddition of diyne and $\mathrm{CO}_{2}$.

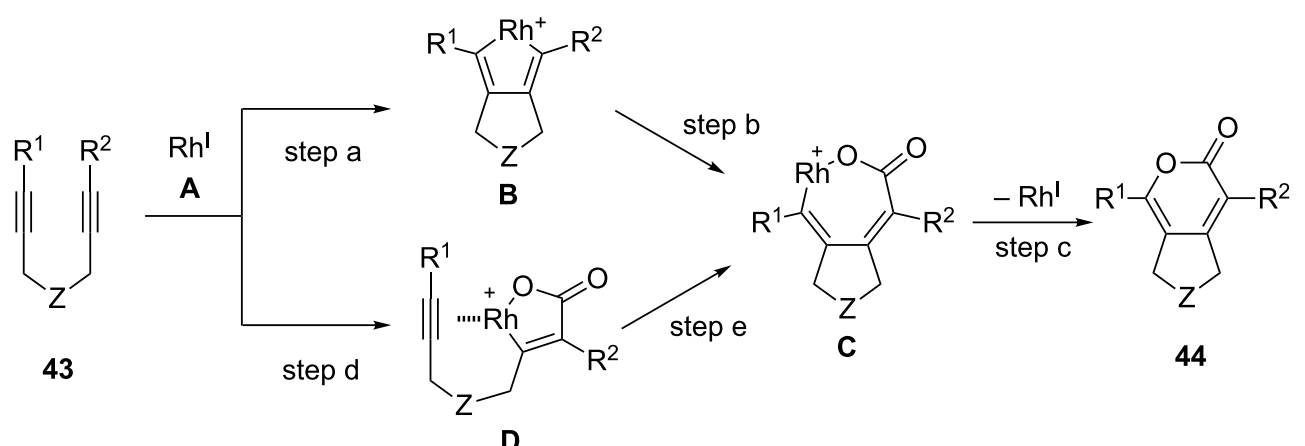

Scheme 41: Proposed reaction pathways for the Rh-catalyzed [2+2+2] cycloaddition of diyne and $\mathrm{CO}_{2}$.

and rhodacycle $\mathbf{D}$ is subsequently formed (step d). Then, the insertion of the alkyne into the $\mathrm{Rh}-\mathrm{C}$ bond occurs to give rhodacycle $\mathbf{C}$ (step e).

\section{Conclusion}

In this review, the Co- and $\mathrm{Rh}$-catalyzed transformation of $\mathrm{CO}_{2}$ via carbon-carbon bond-forming reactions is summarized. Co complexes can catalyze the carboxylation of propargyl acetates and alkenyl triflates. The cobalt-catalyzed reductive carboxylation of $\alpha, \beta$-unsaturated nitriles and carboxyamides proceeds using $\mathrm{Et}_{2} \mathrm{Zn}$. In addition, a cobalt complex proved to be an efficient catalyst in the allylic $\mathrm{C}\left(\mathrm{sp}^{3}\right)-\mathrm{H}$ carboxylation. In the presence of zinc as the reagent, carboxyzincation and the four-component coupling reaction between alkyne, acrylates, $\mathrm{CO}_{2}$, and zinc occur efficiently. Rh complexes also catalyze the carboxylation of aryl and vinylboronic esters, the $\mathrm{C}\left(\mathrm{sp}^{2}\right)-\mathrm{H}$ carboxyla- 
tion of aromatic compounds, and the hydrocarboxylation of styrene derivatives. The Rh-catalyzed [ $2+2+2]$ cycloaddition of diynes and $\mathrm{CO}_{2}$ proceeds to afford pyrenes. Combinations of metals (cobalt or rhodium), substrates, and reducing agents can realize efficient carboxylation reactions using $\mathrm{CO}_{2}$ under mild reaction conditions. Furthermore, the development of novel carboxylation reactions using clean reducing agents such as non-metallic organic reductants such as amine, water, or hydrogen gas can be envisaged in the near future.

\section{ORCID ${ }^{\circledR}$ iDs}

Tetsuaki Fujihara - https://orcid.org/0000-0002-6687-2528

\section{References}

1. Suib, S. L., Ed. New and Future Developments in Catalysis, Activation of Carbon Dioxide; Elsevier: Amsterdam, 2013.

2. Aresta, M., Ed. Carbon Dioxides as Chemical Feedstock; Wiley-VHC: Weinheim, 2010. doi:10.1002/9783527629916

3. Artz, J.; Mueller, T. E.; Thenert, K.; Kleinekorte, J.; Meys, R. I.; Sternberg, A.; Bardow, A.; Leitner, W. Chem. Rev. 2018, 118, 434-504. doi:10.1021/acs.chemrev.7b00435

4. Aresta, M.; Dibenedetto, A.; Angelini, A. Chem. Rev. 2014, 114, 1709-1742. doi:10.1021/cr4002758

5. Luan, Y.-X.; Ye, M. Tetrahedron Lett. 2018, 59, 853-861. doi:10.1016/j.tetlet.2018.01.035

6. Hazari, N.; Heimann, J. E. Inorg. Chem. 2017, 56, 13655-13678. doi:10.1021/acs.inorgchem.7b02315

7. Wu, X.-F.; Zheng, F. Top. Curr. Chem. 2017, 375, No. 4. doi:10.1007/s41061-016-0091-6

8. Börjesson, M.; Moragas, T.; Gallego, D.; Martin, R. ACS Catal. 2016, 6, 6739-6749. doi:10.1021/acscatal.6b02124

9. Juliá-Hernández, F.; Gaydou, M.; Serrano, E.; van Gemmeren, M.; Martin, R. Top. Curr. Chem. 2016, 374, No. 45. doi:10.1007/s41061-016-0045-z

10. Sekine, K.; Yamada, T. Chem. Soc. Rev. 2016, 45, 4524-4532. doi:10.1039/C5CS00895F

11. Wang, S.; Du, G.; Xi, C. Org. Biomol. Chem. 2016, 14, 3666-3676. doi:10.1039/C6OB00199H

12. Yu, D.; Teong, S. P.; Zhang, Y. Coord. Chem. Rev. 2015, 293-294, 279-291. doi:10.1016/j.ccr.2014.09.002

13. Yeung, C. S.; Dong, V. M. Top. Catal. 2014, 57, 1342-1350. doi:10.1007/s11244-014-0301-9

14. Cai, X.; Xie, B. Synthesis 2013, 45, 3305-3324. doi:10.1055/s-0033-1340061

15. Zhang, L.; Hou, Z. Chem. Sci. 2013, 4, 3395-3403. doi:10.1039/c3sc51070k

16. Tsuji, Y.; Fujihara, T. Chem. Commun. 2012, 48, 9956-9964. doi:10.1039/c2cc33848c

17. Manjolinho, F.; Arndt, M.; Gooßen, K.; Gooßen, L. J. ACS Catal. 2012, 2, 2014-2021. doi:10.1021/cs300448v

18. Huang, K.; Sun, C.-L.; Shi, Z.-J. Chem. Soc. Rev. 2011, 40, 2435-2452. doi:10.1039/c0cs00129e

19. Cokoja, M.; Bruckmeier, C.; Rieger, B.; Herrmann, W. A.; Kühn, F. E. Angew. Chem., Int. Ed. 2011, 50, 8510-8537. doi:10.1002/anie.201102010

20. Riduan, S. N.; Zhang, Y. Dalton Trans. 2010, 39, 3347-3357. doi:10.1039/b920163g
21. Tsuji, J. Palladium Reagents and Catalysts; Wiley: Chichester, UK, 2004. doi:10.1002/0470021209

22. Trost, B. M. Acc. Chem. Res. 1996, 29, 355-364. doi:10.1021/ar9501129

23. Trost, B. M. Acc. Chem. Res. 1980, 13, 385-393. doi:10.1021/ar50155a001

24. Torii, S.; Tanaka, H.; Hamatani, T.; Morisaki, K.; Jutand, A.; Peluger, F.; Fauvarque, J.-F. Chem. Lett. 1986, 15, 169-172. doi:10.1246/cl.1986.169

25. Medeiros, M. J.; Pintaric, C.; Olivero, S.; Dunach, E. Electrochim. Acta 2011, 56, 4384-4389. doi:10.1016/j.electacta.2010.12.066

26. Moragas, T.; Cornella, J.; Martin, R. J. Am. Chem. Soc. 2014, 136, 17702-17705. doi:10.1021/ja509077a

27. Mita, T.; Higuchi, Y.; Sato, Y. Chem. - Eur. J. 2015, 21, 16391-16394. doi:10.1002/chem.201503359

28. León, T.; Correa, A.; Martin, R. J. Am. Chem. Soc. 2013, 135, 1221-1224. doi:10.1021/ja311045f

29. Nogi, K.; Fujihara, T.; Terao, J.; Tsuji, Y. Chem. Commun. 2014, 50, 13052-13055. doi:10.1039/C4CC03644A

30. Qian, X.; Auffrant, A.; Felouat, A.; Gosmini, C. Angew. Chem., Int. Ed. 2011, 50, 10402-10405. doi:10.1002/anie.201104390

31. Correa, A.; Martín, R. J. Am. Chem. Soc. 2009, 131, 15974-15975. doi:10.1021/ja905264a

32. Fujihara, T.; Nogi, K.; Xu, T.; Terao, J.; Tsuji, Y. J. Am. Chem. Soc. 2012, 134, 9106-9109. doi:10.1021/ja303514b

33. Nogi, K.; Fujihara, T.; Terao, J.; Tsuji, Y. J. Org. Chem. 2015, 80, 11618-11623. doi:10.1021/acs.joc.5b02307

34. Isayama, S.; Mukaiyama, T. Chem. Lett. 1989, 18, 2005-2008. doi:10.1246/cl.1989.2005

35. Hayashi, C.; Hayashi, T.; Kikuchi, S.; Yamada, T. Chem. Lett. 2014, 43, 565-567. doi:10.1246/cl.131163

36. Hayashi, C.; Hayashi, T.; Yamada, T. Bull. Chem. Soc. Jpn. 2015, 88, 862-870. doi:10.1246/bcsj.20150043

37. Michigami, K.; Mita, T.; Sato, Y. J. Am. Chem. Soc. 2017, 139, 6094-6097. doi:10.1021/jacs.7b02775

38. Knochel, P.; Leuser, H.; Gong, L.-Z.; Perrone, S.; Kneisel, F. F. Polyfunctional Zinc Organometallics for Organic Synthesis. Handbook of Functionalized Organometallics; Wiley-VCH: Weinheim, 2005; Vol. 1, pp 251-346. doi:10.1002/9783527619467.ch7

39. Knochel, P.; Singer, R. D. Chem. Rev. 1993, 93, 2117-2188. doi:10.1021/cr00022a008

40. Nogi, K.; Fujihara, T.; Terao, J.; Tsuji, Y. J. Am. Chem. Soc. 2016, 138, 5547-5550. doi:10.1021/jacs.6b02961

41. Fillon, H.; Gosmini, C.; Périchon, J. J. Am. Chem. Soc. 2003, 125, 3867-3870. doi:10.1021/ja0289494

42. Wang, C.-C.; Lin, P.-S.; Cheng, C.-H. J. Am. Chem. Soc. 2002, 124, 9696-9697. doi:10.1021/ja026543।

43. Skubi, K. L.; Blum, T. R.; Yoon, T. P. Chem. Rev. 2016, 116, 10035-10074. doi:10.1021/acs.chemrev.6b00018

44. Romero, N. A.; Nicewicz, D. A. Chem. Rev. 2016, 116, 10075-10166. doi:10.1021/acs.chemrev.6b00057

45. Prier, C. K.; Rankic, D. A.; MacMillan, D. W. C. Chem. Rev. 2013, 113, 5322-5363. doi:10.1021/cr300503r

46. Masuda, Y.; Ishida, N.; Murakami, M. J. Am. Chem. Soc. 2015, 137, 14063-14066. doi:10.1021/jacs.5b10032

47. Seo, H.; Katcher, M. H.; Jamison, T. F. Nat. Chem. 2017, 9, 453-456. doi:10.1038/nchem.2690

48. Shimomaki, K.; Murata, K.; Martin, R.; Iwasawa, N. J. Am. Chem. Soc. 2017, 139, 9467-9470. doi:10.1021/jacs.7b04838 
49. Hou, J.; Ee, A.; Feng, W.; Xu, J.-H.; Zhao, Y.; Wu, J.

J. Am. Chem. Soc. 2018, 140, 5257-5263. doi:10.1021/jacs.8b01561

50. Miyaura, N.; Suzuki, A. Chem. Rev. 1995, 95, 2457-2483. doi:10.1021/cr00039a007

51. Suzuki, A.; Brown, H. C. Suzuki Coupling. Organic Syntheses via Boranes; Aldrich: Milwaukee, 2003; Vol. 3.

52. Hayashi, T.; Yamasaki, K. Chem. Rev. 2003, 103, 2829-2844. doi:10.1021/cr020022z

53. Miyaura, N. Bull. Chem. Soc. Jpn. 2008, 81, 1535-1553. doi:10.1246/bcsj.81.1535

54. Ukai, K.; Aoki, M.; Takaya, J.; Iwasawa, N. J. Am. Chem. Soc. 2006, 128, 8706-8707. doi:10.1021/ja061232m

55. Takaya, J.; Tadami, S.; Ukai, K.; Iwasawa, N. Org. Lett. 2008, 10, 2697-2700. doi:10.1021/ol800829q

56. Ohishi, T.; Nishiura, M.; Hou, Z. Angew. Chem., Int. Ed. 2008, 47, 5792-5795. doi:10.1002/anie.200801857

57. Boogaerts, I. I. F.; Fortman, G. C.; Furst, M. R. L.; Cazin, C. S. J.; Nolan, S. P. Angew. Chem., Int. Ed. 2010, 49, 8674-8677. doi:10.1002/anie.201004153

58. Zang, L.; Cheng, J.; Ohishi, T.; Hou, Z. Angew. Chem., Int. Ed. 2010 49, 8670-8673. doi:10.1002/anie.201003995

59. Mizuno, H.; Takaya, J.; Iwasawa, N. J. Am. Chem. Soc. 2011, 133, 1251-1253. doi:10.1021/ja109097z

60. Suga, T.; Mizuno, H.; Takaya, J.; Iwasawa, N. Chem. Commun. 2014, 50, 14360-14363. doi:10.1039/C4CC06188H

61.Suga, T.; Saitou, T.; Takaya, J.; Iwasawa, N. Chem. Sci. 2017, 8, 1454-1462. doi:10.1039/C6SC03838G

62. Fu, L.; Li, S.; Cai, Z.; Ding, Y.; Guo, Z.-Q.; Zhou, L.-P.; Yuan, D.; Sun, Q.-F.; Li, G. Nat. Catal. 2018, 1, 469-478. doi:10.1038/s41929-018-0080-y

63. Fujihara, T.; Xu, T.; Semba, K.; Terao, J.; Tsuji, Y. Angew. Chem., Int. Ed. 2011, 50, 523-527. doi:10.1002/anie.201006292

64. Li, S.; Yuan, W.; Ma, S. Angew. Chem., Int. Ed. 2011, 50, 2578-2582. doi:10.1002/anie.201007128

65. Miao, B.; Zheng, Y.; Wu, P.; Li, S.; Ma, S. Adv. Synth. Catal. 2017, 359, 1691-1707. doi:10.1002/adsc.201700086

66. Wang, X.; Nakajima, M.; Martin, R. J. Am. Chem. Soc. 2015, 137, 8924-8927. doi:10.1021/jacs.5b05513

67. Williams, C. M.; Johnson, J. B.; Rovis, T. J. Am. Chem. Soc. 2008, 130, 14936-14937. doi:10.1021/ja8062925

68. Takaya, J.; Miyama, K.; Zhu, C.; Iwasawa, N. Chem. Commun. 2017, 53, 3982-3985. doi:10.1039/C7CC01377A

69. Takaya, J.; Iwasawa, N. J. Am. Chem. Soc. 2008, 130, 15254-15255. doi:10.1021/ja806677w

70. Zhu, C.; Takaya, J.; Iwasawa, N. Org. Lett. 2015, 17, 1814-1817. doi:10.1021/acs.orglett.5b00692

71. Tani, Y.; Kuga, K.; Fujihara, T.; Terao, J.; Tsuji, Y. Chem. Commun. 2015, 51, 13020-13023. doi:10.1039/C5CC03932K

72. Takaya, J.; Sasano, K.; Iwasawa, N. Org. Lett. 2011, 13, 1698-1701. doi:10.1021/ol2002094

73. Gui, Y.-Y.; Hu, N.; Chen, X.-W.; Liao, L.-L.; Ju, T.; Ye, J.-H.; Zhang, Z.; Li, J.; Yu, D.-G. J. Am. Chem. Soc. 2017, 139, 17011-17014. doi:10.1021/jacs.7b10149

74. Kawashima, S.; Aikawa, K.; Mikami, K. Eur. J. Org. Chem. 2016, 3166-3170. doi:10.1002/ejoc.201600338

75. Murata, K.; Numasawa, N.; Shimomaki, K.; Takaya, J.; Iwasawa, N. Chem. Commun. 2017, 53, 3098-3101. doi:10.1039/C7CC00678K

76. Louie, J.; Gibby, J. E.; Farnworth, M. V.; Tekavec, T. N. J. Am. Chem. Soc. 2002, 124, 15188-15189. doi:10.1021/ja027438e
77. Tsuda, T.; Morikawa, S.; Sumiya, R.; Saegusa, T. J. Org. Chem. 1988, 53, 3140-3145. doi:10.1021/jo00249a003

78. Inoue, Y.; Itoh, Y.; Hashimoto, H. Chem. Lett. 1978, 7, 633-634. doi:10.1246/cl.1978.633

79. Ishii, M.; Mori, F.; Tanaka, K. Chem. - Eur. J. 2014, 20, 2169-2174. doi:10.1002/chem.201304623

\section{License and Terms}

This is an Open Access article under the terms of the Creative Commons Attribution License

(http://creativecommons.org/licenses/by/4.0). Please note that the reuse, redistribution and reproduction in particular requires that the authors and source are credited.

The license is subject to the Beilstein Journal of Organic Chemistry terms and conditions:

(https://www.beilstein-journals.org/bjoc)

The definitive version of this article is the electronic one which can be found at: doi:10.3762/bjoc. 14.221 